\title{
Control of Boost Converter Module for Open-End Winding Permanent Magnet Motor Based, Dual Inverter Drive
}

by

\section{Ryan M. Brody}

Bachelor of Science in Electrical Engineering, University of Pittsburgh, 2018

\author{
Submitted to the Graduate Faculty of the \\ Swanson School of Engineering in partial fulfillment \\ of the requirements for the degree of \\ Master of Science in Electrical and Computer Engineering
}

University of Pittsburgh 


\section{UNIVERSITY OF PITTSBURGH}

\section{SWANSON SCHOOL OF ENGINEERING}

This thesis was presented

by

\section{Ryan M. Brody}

It was defended on

March 24, 2020

and approved by

Brandon Grainger, PhD., Assistant Professor, Department of Electrical and Computer Engineering

Robert Kerestes, PhD., Assistant Professor, Department of Electrical and Computer Engineering

Mahmoud El Nokali, PhD., Associate Professor, Department of Electrical and Computer Engineering

Thesis Advisor: Brandon Grainger, PhD., Assistant Professor, Department of Electrical and Computer Engineering 
Copyright (C) by Ryan M. Brody

2020 


\title{
Control of Boost Converter Module for Open-End Winding Permanent Magnet Motor Based, Dual Inverter Drive
}

\author{
Ryan M. Brody, M.S.
}

University of Pittsburgh, 2020

This work explains how to control a boost converter module to vary the DC link voltage of a dual inverter motor drive. Doing so is shown to extend the speed range of open-end winding permanent magnet synchronous motors (OWPMSM) compared to using flux weakening control, enabling the use of more efficient and power dense high-speed motors. Such a speed range can be obtained by simply increasing the battery voltage, thus increasing the DC link voltage, and using flux weakening control. However, depending on the rebalancing technique used, cell imbalances in high-voltage batteries can decrease the efficiency and/or the battery lifetime, both of which are sensitive metrics in electric vehicles (EVs). Splitting the required battery voltage between two independent sources to drive the OWPMSM and using the boost converter modules to further increase the DC link voltage as needed extends the speed range while keeping the individual battery voltages low enough to prevent exacerbating cell-balancing issues. Furthermore, by adding the boost converter modules, the motor drive can satisfy the maximum torque per ampere (MTPA) condition at all speeds. Doing so decreases the maximum stator current above base speed compared to flux weakening control while maintaining the same torque-speed curve, thus lowering conduction losses. Simulation results from PLECS confirm the extended speed range and lower conduction losses of the topology compared to a conventional permanent magnet synchronous motor (PMSM) drive and a dual inverter drive without the boost converter modules. 


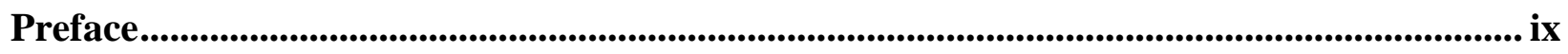

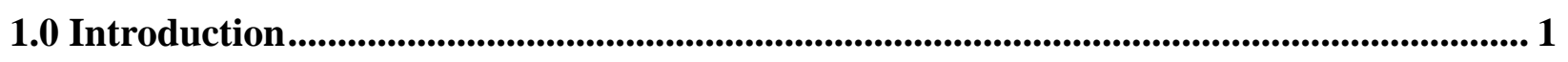

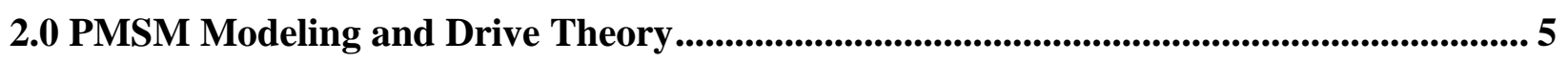

2.1 Space Vector Representation and Transformation into the dq-Frame.................... 6

2.2 Control of a Permanent Magnet-Based Motor ............................................................ 13

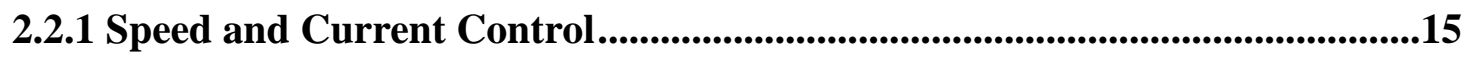

2.2.2 MTPA Control - Below Base Speed ..........................................................17

2.2.3 Flux Weakening Control - Above Base Speed .............................................18

2.3 Relevant PMSM Motor Drives from Literature............................................................. 20

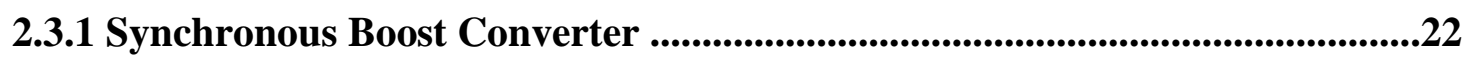

2.3.2 Two-level, Three-phase Voltage Source Inverter (VSI) ...............................25

3.0 Proposed OWPMSM Motor Drive with Boost Converter Modules ................................ 31

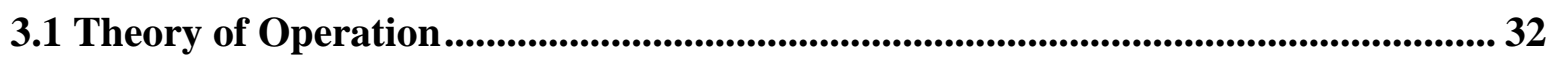

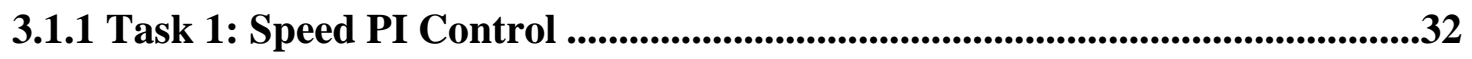

3.1.2 Task 2: MTPA and Current PI Control ..........................................................32

3.1.3 Task 3: Stator Voltage Decomposition .............................................................33

3.1.4 Task 4: Battery Current Calculator ............................................................37

3.2 Comparison to Relevant PMSM Drives ......................................................................... 38

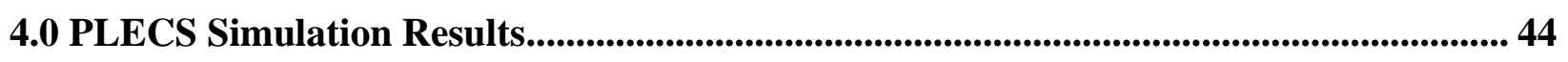

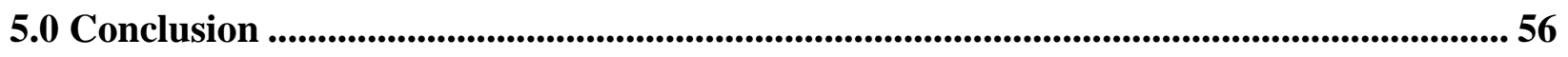

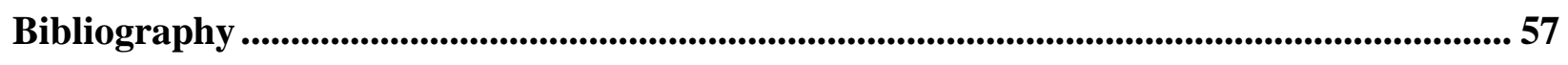




\section{List of Tables}

Table 1 - Necessary Simulation Parameters ........................................................................ 44

Table 2 - Base Values for Machine Variables ........................................................................................ 44 


\section{List of Figures}

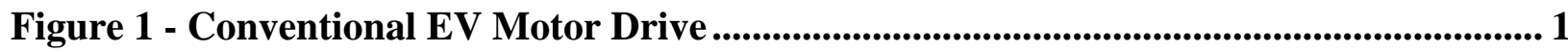

Figure 2 - Dual Inverter Drive ............................................................................................................... 2

Figure 3 - Example Space Vector in the abc Reference Frame ................................................. 7

Figure 4 - Space Vector in Rotating Reference Frame......................................................... 8

Figure 5 - PMSM and OWPMSM d-axis equivalent circuit.................................................... 11

Figure 6 - PMSM and OWPMSM q-axis equivalent circuit.................................................. 11

Figure 7 - PMSM and OWPMSM 0-axis equivalent circuit ........................................... 12

Figure 8 - Typical Control Block Diagram for PMSM Drives .............................................. 15

Figure 9 - Synchronous Boost Converter.......................................................................................... 23

Figure 10 - Schematic of Two-Level, Three-phase Voltage Source Inverter ....................... 26

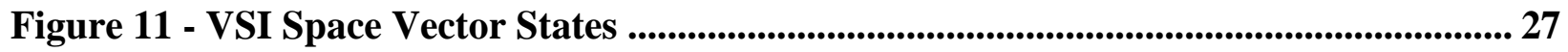

Figure 12 - Dual Inverter Drive Space Vector States: VDC1 = VDC2................................... 29

Figure 13 - Dual Inverter Drive Space Vector States:VDC1 = 2VDC2 ............................ 30

Figure 14 - Block Diagram of Dual Inverter Drive with Boost Converter Module ................ 31

Figure 15 - Sectors for Space Vector Decomposition ...................................................................... 34

Figure 16 - Example Space Vector Decomposition for Proposed Controller ......................... 35

Figure 17 - Phasor Diagram Below Base Speed (MTPA) .............................................................. 39

Figure 18 - Phasor Diagram Above Base Speed (Flux Weakening) ...................................... 40

Figure 19 - Capability Curve for PMSM Drives with Flux Weakening ................................... 41

Figure 20 - Phasor Diagram Above Base Speed (Boost Converter Module)........................... 42

Figure 21 - Capability Curve for PMSM Drives with Boost Converter Modules ................. 43 
Figure 22 - Torque-Speed Curve for Dual Inverter Drive with Boost Converter Modules. 46

Figure 23 - Step Response for Speed and Resultant Torque Production

Figure 24 - Power Production vs. Speed for Dual Inverter Drive with Boost Converter

Modules. 48

Figure 25 - Stator Magnitude and Angle vs. Speed 49

Figure 26 - Steady State Phase Currents vs. Time.............................................................. 50

Figure 27 - Resultant Voltages During Step Change in Speed .......................................... 52

Figure 28 - Voltage vs. Speed During a Step Change in Voltage............................................ 53

Figure 29 - Battery Current During a Step Change in Speed................................................ 54

Figure 30 - Switching Funciton at Steady State for Boost Converter Module ....................... 55 


\section{Preface}

While this thesis bears only my name, many people in my life have contributed to this accomplishment in significant ways. To rectify the unfairness of this limitation, I would like to take a few paragraphs to honor those who deserve recognition. I thank God for all of those mentioned below and those whom I had not the time to name, for I am truly blessed to be loved and cared for by so many.

First, I would like to thank my parents, Michael and Debra Brody. Throughout my life, they have consistently put my needs before their own and provided me unconditional love and support that has freed me to pursue my passions. As two of the hardest working people I know, they have demonstrated to me the value of honest work and giving back to others along the way, and they have inspired in me a similar work ethic.

Next, I would like to thank my advisor, Dr. Brandon Grainger. I first met him as undergraduate student without any research experience, and through his guidance I have grown to become the author of this thesis. When I first started graduate school, I remember doubting my ability to produce this very document for a variety of reasons, among them the academic rigor of doing so and chronic medical conditions I have been working through. Thanks to Brandon's support, advice and encouragement, I am here today proud of my work.

I would also like to thank all of my professors and for creating an enriching learning environment as the University of Pittsburgh. In particular, I would like to thank committee member Dr. Robert Kerestes. He has been a valuable mentor to me, as both an undergraduate and graduate student. 
Finally, I would like to thank the rest of my friends and family not mentioned here. The overwhelming love and support I receive from them outside of the University makes it much easier to focus on my work when needed. In particular, I would like to thank my girlfriend, Grace McHale, for all of the emotional support she has provided me throughout our relationship, and my older brother, Zachary Brody, for showing me what it means to never give up. 


\subsection{Introduction}

An OWPMSM is a type of PMSM with no neutral point. Instead, opening the neutral connection electrically isolates each winding from the others, and the windings therefore can accept voltage from both ends [1]. As such, separate inverters can drive each end of the windings, mimicking the behavior of an H-bridge inverter topology but using two separate half-bridge inverters. Throughout this work, the phrase "dual inverter drive" [2] refers to using two inverters to drive a OWPMSM, although other names for the topology exist, such as "cascaded inverter" [3] and "doubled-ended inverter"[1]. Figure 1 shows topologies for a conventional PMSM motor drive for an EV [4] compared to a dual inverter drive for an OWPMSM [1] in Figure 2. Although the designation is arbitrary, for the sake of consistency, this work refers to the "primary inverter" as the top inverter related to variables with a subscript "1", while "secondary inverter" refers to the bottom related to variables with a subscript " 2 ".

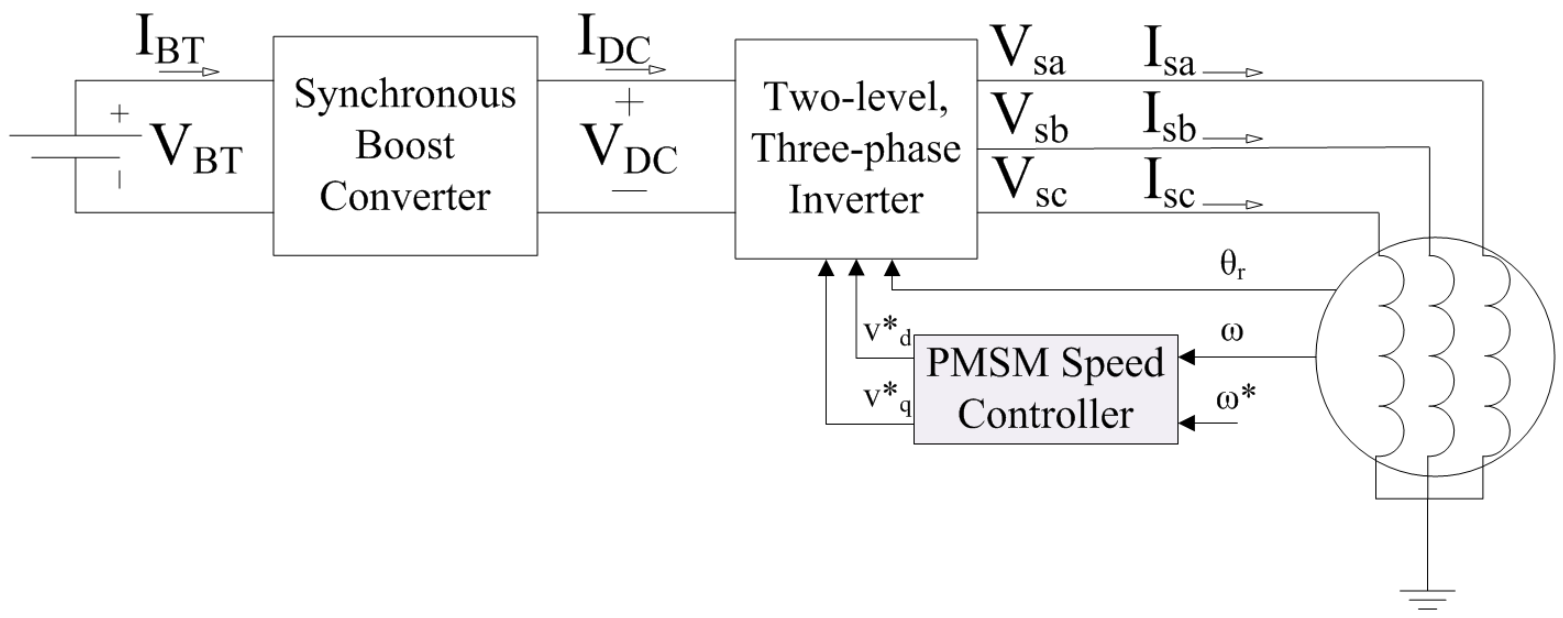

Figure 1 - Conventional EV Motor Drive 


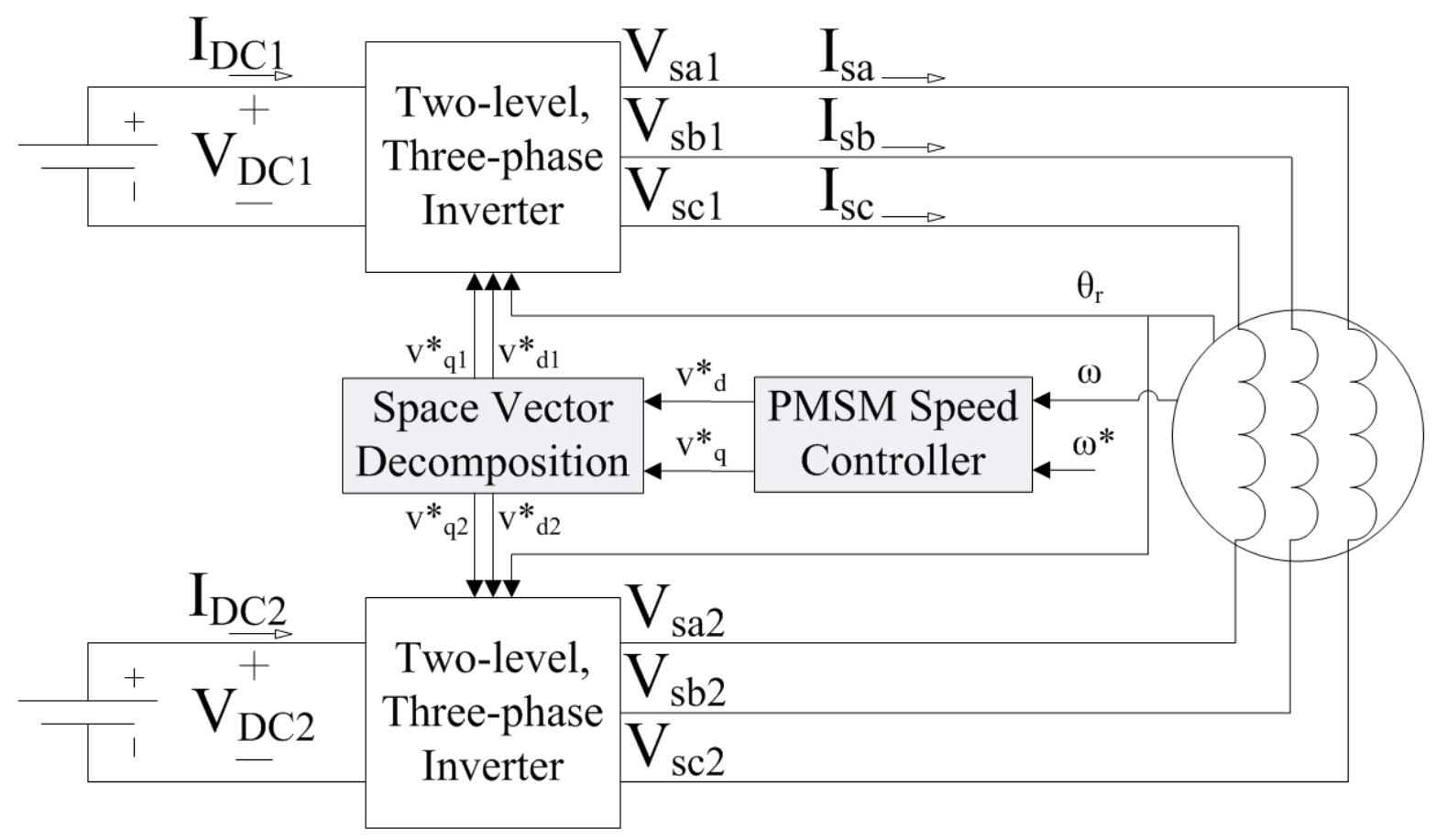

Figure 2 - Dual Inverter Drive

The dual inverter drive has several advantages in EV applications. First and foremost, it extends the speed range of the PMSM by increasing the DC link voltage without increasing the voltage of an individual battery [2],[5]. PMSMs have become common in EVs due to their higher efficiency and power density [6]. However, these types of motors have a fairly limited speed range because of the inability to weaken the rotor flux. The back EMF, a voltage induced in the stator windings due to a change in flux linkage as the rotor rotates, grows proportionally with speed. To induce current in the stator windings, the motor drive must supply a voltage greater than the back EMF to the stator. The field current cannot be lowered in these machines to reduce the back EMF at high speeds like in wound rotor synchronous machine, so the maximum voltage available to the stator primarily limits the speed range of the PMSM [7]. 
The dual inverter drive supplies voltage to both ends of the stator windings, so the maximum stator voltage doubles without increasing the required battery voltage of an individual battery. This facilitates the use of smaller, more efficient motors [2] without increasing battery balancing complexity, which increases exponentially with battery voltage and can negatively impact efficiency, battery calendrer life, and cost [8], [9]. Due to the impact on vehicle range and lifetime vehicle cost for consumers, all of these are critical metrics to consider when designing EVs [10], [11].

Other commonly listed advantages of the dual inverter drive are multilevel output voltages that improve THD, fault tolerance, and the low cost/high maturity of the VSI modules used [5]. More recently, it has been shown that the dual inverter drive can integrate both three phase AC [12] and DC fast charging [13] capabilities in EVs while adding few components, a feat expected to increase the pace at which consumers adopt EVs by decreasing charging time and the cost of charging infrastructure. The main disadvantages of this topology are the increased probability of a single point of failure [5] and the increase in control complexity.

To this point, literature has ignored the benefits of using a DC/DC converter in the dual inverter drive because the inverters can adequately control the flow of energy and power in the system during driving without additional power electronics [1], and it can control the battery current ripple during charging [13]. Despite this fact, most EV applications still require a DC/DC converter for important tasks related to maintaining battery health, such as voltage regulation and battery current control during regenerative breaking [14]. Furthermore, boosting the DC link voltage at high speeds has been shown to improve the inverter efficiency [15] and the efficiency and speed range of the motor [6] in conventional EV motor drives. 
Considering the benefits of the DC/DC converter presented in these studies, this paper presents a dual inverter drive topology with DC/DC converter modules that boost the DC link voltage at high speeds, and it proposes and control scheme for the topology. Results shows that using the proposed topology and control improves the motor performance by increasing the speed range compared to flux weakening operation while also lowering conduction losses. The proposed a control scheme for the new topology is based off of combination of existing solutions for conventional PMSM drives and dual inverter drives without boost converter modules. 


\subsection{PMSM Modeling and Drive Theory}

This section provides background information on the mathematical modeling of PMSM and the associated OWPMSM along with relevant information regarding their respective motor drives. [7] provides a detailed derivation of the PMSM model used in this work. Assuming equal stator winding resistance, $R_{s},(2-1)-(2-5)$ describe the equivalent circuit of the motor. $v_{a b c s}$ and $i_{a b c s}$ are vectors representing the phase voltages and currents, respectively, and $v_{n}$ is the neutral voltage. $L_{S}$ is the inductance matrix, where the diagonal terms are the self-inductance of each phase, and the off-diagonal terms are the mutual inductance between phases.

$\lambda_{a b c s}$ is the flux linkage of each winding and has two contributions. The first, from the stator, is produced by the current in the windings, and the second, from the rotor, is the flux linkage due to the presence of permanent magnets in the rotor, $\lambda_{a f}$. A voltage is induced in the stator windings during rotation as a result of the change in the stator winding flux linkage. In particular, the voltage induced by the portion of flux linkage contributed by the rotor is called the back EMF, but the current in the windings also generate flux according to the inductance of the windings, shown in (2-4), due to the magnetic coupling of the windings.

From these equations come equations for average power and torque produced by the motor drive in (2-6) and (2-7), respectively. (2-7) also relates the torque production to the motor speed using Newton's Second Law for Rotation, where $\omega_{m}$ is the mechanical speed of the motor. Finally, (2-8) relates the mechanical speed and electrical frequency, $\omega_{r}$, by the number of poles, $P$. 


$$
\begin{gathered}
v_{a b c s}=\left[\begin{array}{l}
v_{a}(t) \\
v_{b}(t) \\
v_{c}(t)
\end{array}\right] \\
i_{a b c s}=\left[\begin{array}{l}
i_{a}(t) \\
i_{b}(t) \\
i_{c}(t)
\end{array}\right] \\
L_{s}=\left[\begin{array}{l}
L_{a a} L_{a b} L_{a c} \\
L_{b a} L_{b b} L_{b c} \\
L_{c a} L_{c b} L_{c c}
\end{array}\right] \\
\lambda_{a b c s}=L_{s} i_{a b c s}+\lambda_{a f}\left[\begin{array}{l}
\cos \left(\theta_{r}\right) \\
\cos \left(\theta_{r}-120^{\circ}\right) \\
\cos \left(\theta_{r}+120^{\circ}\right)
\end{array}\right] \\
v_{a b c s}-v_{n}=R_{s} i_{a b c s}+\frac{d \lambda_{a b c s}}{d t} \\
P_{e}=v_{a b c s} * i_{a b c s}^{\prime} \\
\frac{P}{2}\left(i_{a b c s} * \lambda_{a b c s}^{\prime}\right)=J \frac{d \omega_{m}}{d t}+B \omega_{m}+T_{l} \\
\omega_{m}=\frac{P}{2} \omega_{r}
\end{gathered}
$$

\subsection{Space Vector Representation and Transformation into the dq-Frame}

In power systems, any three phase signal can be transformed into a space vector with a magnitude and phase [16]. However, the axes can be oriented in different ways using a transformation matrix to describe the same vector in different frames of reference. This section reviews two frames of reference used to model a PMSM or OWPMSM: the stationary abc-frame and the rotating dq0-frame.

First, the ab-frame, where the a-axis is the angle reference, and the b- and c-axis are displaced by $\pm 120^{\circ}$, respectively. The linear combination of the phase signals with their respective axis' unit vectors essentially gives the space vector representation of the signal, $\vec{f}$, as a complex number, shown in (2-9). The coefficient is included so that that magnitude of the space vector equals the magnitude of each phase under balanced conditions. Figure 3 demonstrates the process 
of constructing a space vector using the abc-axes. In a balanced three-phase system, the space vector $\vec{f}$ will have a constant magnitude and rotate with a constant speed around the orgin.

$$
\begin{gathered}
f_{a b c}=\left[\begin{array}{l}
f_{a}(t) \\
f_{b}(t) \\
f_{c}(t)
\end{array}\right] \\
\vec{f}=\frac{2}{3}\left[e^{j 0^{\circ}} e^{j 120^{\circ}} e^{-j 120^{\circ}}\right] \cdot f_{a b c} \\
\vec{f}=\frac{2}{3}\left(f_{a}(t) e^{j 0^{\circ}}+f_{b}(t) e^{j 120^{\circ}}+f_{c}(t) e^{-j 120^{\circ}}\right)
\end{gathered}
$$

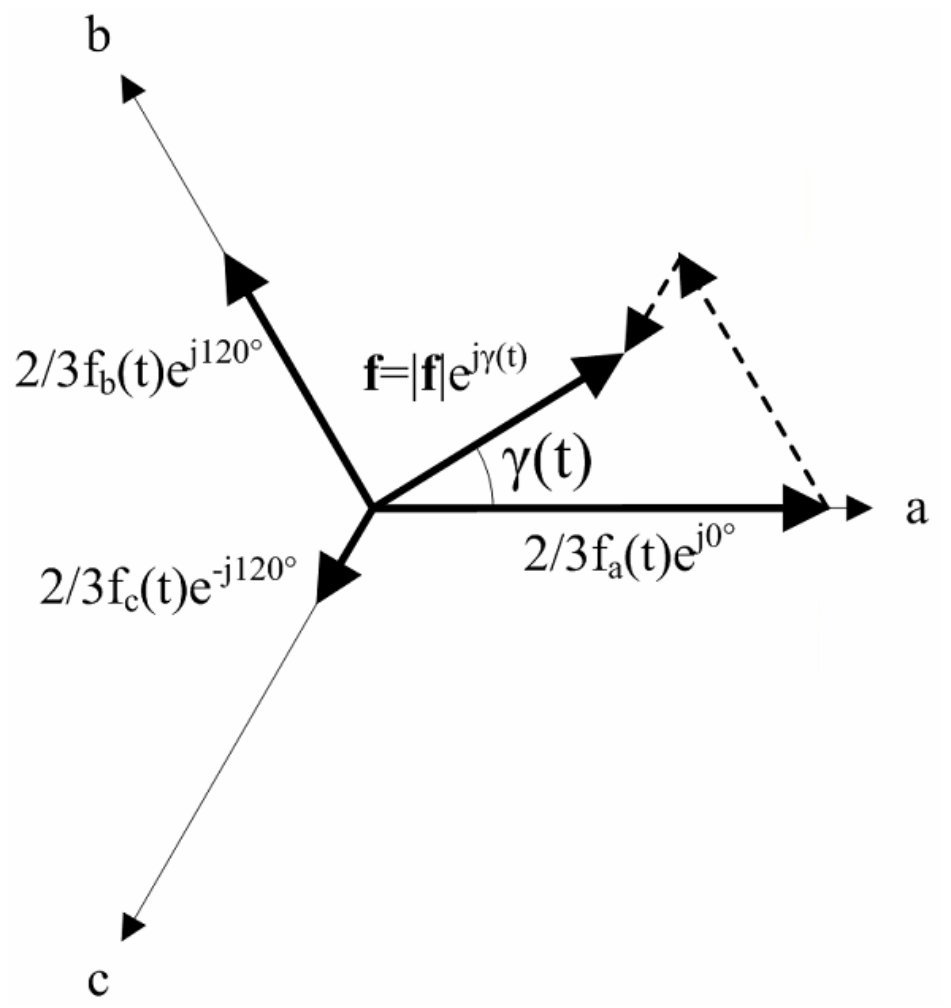

Figure 3 - Example Space Vector in the abc Reference Frame 
Next, the dq0-frame. Figure 4 shows how to obtain the dq0-axes from the abc-axes. In this reference frame, the direct axis (d-axis) is the angle reference, obtained by applying a phase shift of $\alpha(t)$ to the a-axis, and the quadrature axis (q-axis) is shifted by $90^{\circ}$ relative to the $\mathrm{d}$-axis. These two axes can completely describe a balanced three-phase sinusoidal system as constant complex number. The final axis, the zero axis ( 0 -axis) represents the common mode of the signal. Under balanced conditions, this component can be neglected.

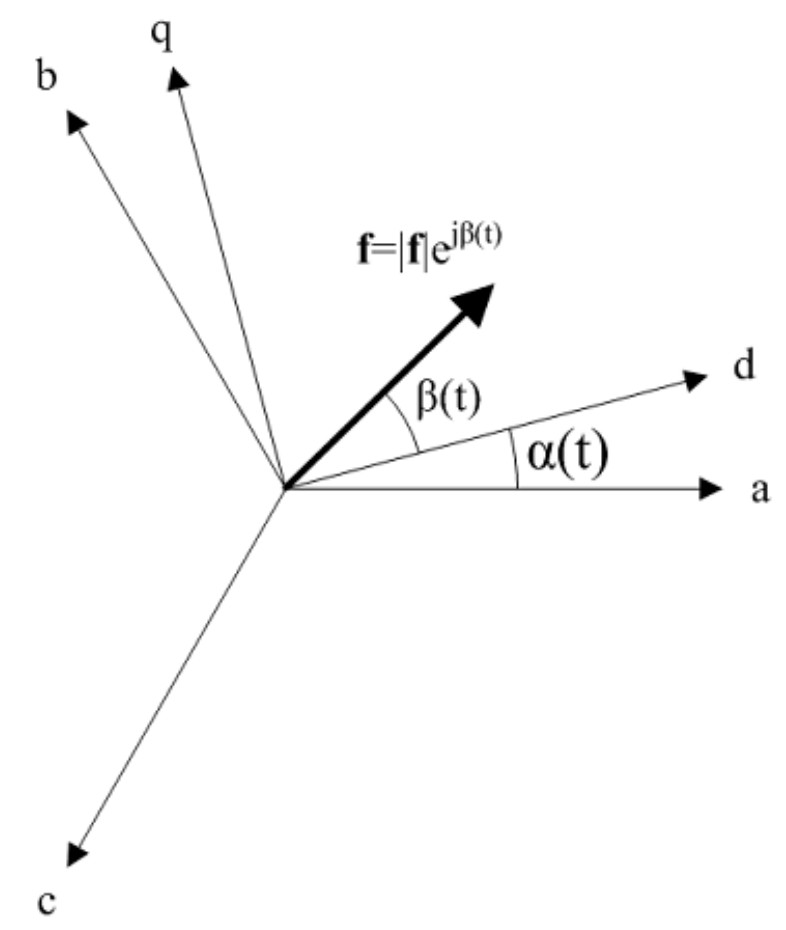

Figure 4 - Space Vector in Rotating Reference Frame

Using this transformation, the angle $\alpha(t)$ can be selected so that the axes rotate at the same speed as the space vector in the abc-frame, making the space vector constant in the dq0-frame under the balanced conditions. In the case of a motor drive, setting $\alpha(t)=\theta_{r}(t)$, where $\theta_{r}$ is the angle of the rotor with respect to the a-axis, synchronizes the dq0-axes with the rotor, making the 
vector components behave more like DC values that can be regulated using linear PI controllers. In this case, when $\alpha(t)=\theta_{r}(t)$, the space vector is said to be "in the rotor reference frame".

The Park's and Clarke's transformations, applied sequentially, directly transform a column vector of the three-phase signal into a vector in the dq0-frame, explained in [7] and [16]. (2-10) (2-12) define the so-called dq0-transformation, $T$, where $f_{d q 0}^{r}$ is a column vector representing the components of $\vec{f}$ in the dq0-frame. Again, any angle $\alpha(t)$ can be substituted in for $\theta_{r}$, and this particular angle is chosen to simplify the control of the system.

$$
\begin{aligned}
& T=\frac{2}{3}\left[\begin{array}{ccc}
\cos \left(\theta_{r}\right) & \cos \left(\theta_{r}-\frac{2 \pi}{3}\right) & \cos \left(\theta_{r}+\frac{2 \pi}{3}\right) \\
\sin \left(\theta_{r}\right) & \sin \left(\theta_{r}-\frac{2 \pi}{3}\right) & \sin \left(\theta_{r}+\frac{2 \pi}{3}\right) \\
\frac{1}{2} & \frac{1}{2} & \frac{1}{2}
\end{array}\right] \\
& T^{-1}=\left[\begin{array}{ccc}
\cos \left(\theta_{r}\right) & \sin \left(\theta_{r}\right) & 1 \\
\cos \left(\theta_{r}-\frac{2 \pi}{3}\right) & \sin \left(\theta_{r}-\frac{2 \pi}{3}\right) & 1 \\
\cos \left(\theta_{r}+\frac{2 \pi}{3}\right) & \sin \left(\theta_{r}+\frac{2 \pi}{3}\right) & 1
\end{array}\right] \\
& f_{\mathrm{dq} 0}^{r}=\left[\begin{array}{l}
f_{d}(t) \\
f_{q}(t) \\
f_{0}(t)
\end{array}\right]=T f_{a b c}^{r} \\
& f_{d q}^{r}=\left[\begin{array}{l}
f_{d}(t) \\
f_{q}(t)
\end{array}\right] \\
& \vec{f}=\left[\begin{array}{ll}
e^{j \alpha(t)} & e^{j\left(\alpha(t)+90^{\circ}\right)}
\end{array}\right] \cdot f_{d q}^{r}
\end{aligned}
$$


In this work, a variable with a superscript " $r$ " denotes a column vector of space vector components in the rotor reference frame. Additionally, for much of this work, the 0-axis components will be ignored, as shown in (2-13), and this will be implied by omitting the " 0 " from the subscript. In this case, the space vector $\vec{f}$ described in (2-14) is equivalent to (2-9) in the abcframe.

Now, applying the transformation matrix $T$ to equations (2-1)-(2-7) yields the motor model in the rotor reference frame, shown in (2-15)-(2-17). This model is more useful from a control perspective because the stator voltage and current are DC values for a balanced system, so PI control can effectively regulate the current in the motor as it would any RL circuit. Notice that the back EMF, $E_{i}^{r}$, is proportional to speed, so for a given $i_{s}^{r}$, the motor requires more voltage at high speeds to overcome the higher back EMF. These equations correspond to equivalent circuits for each axis, shown in Figure 5 - Figure 7 below.

$$
\begin{gathered}
v_{d q 0 s}^{r}=\left[\begin{array}{c}
v_{d s}^{r} \\
v_{q s}^{r} \\
v_{0 s}^{r}
\end{array}\right]=T * v_{a b c s} \\
i_{d q 0 s}^{r}=\left[\begin{array}{l}
i_{d s}^{r} \\
i_{q s}^{r} \\
i_{0 s}^{r}
\end{array}\right]=T * i_{a b c s} \\
E_{d q 0}^{r}=\left[\begin{array}{c}
0 \\
\omega_{r} \lambda_{a f} \\
0
\end{array}\right] \\
v_{d q 0 s}^{r}=\left[\begin{array}{ccc}
R_{s} & 0 & 0 \\
0 & R_{s} & 0 \\
0 & 0 & R_{0}
\end{array}\right] i_{d q 0 s}^{r}+\left(\left[\begin{array}{ccc}
L_{d} & 0 & 0 \\
0 & L_{q} & 0 \\
0 & 0 & L_{0}
\end{array}\right] \frac{d}{d t} i_{d q 0 s}^{r}+\left[\begin{array}{c}
-\omega_{r} L_{q} i_{q s}^{r} \\
\omega_{r} L_{d} i_{d s}^{r} \\
0
\end{array}\right]\right)+E_{d q 0}^{r} \\
P_{e}=\frac{3}{2} v_{d q 0 s}^{r} * i_{d q 0 s}^{r} \\
T_{e}=\frac{3}{2} \frac{P}{2}\left(\lambda_{a f} i_{q s}^{r}+\left(L_{d}-L_{q}\right) i_{q s}^{r} i_{d s}^{r}\right)=J \frac{d \omega_{m}}{d t}+T_{l}+B \omega_{m}
\end{gathered}
$$




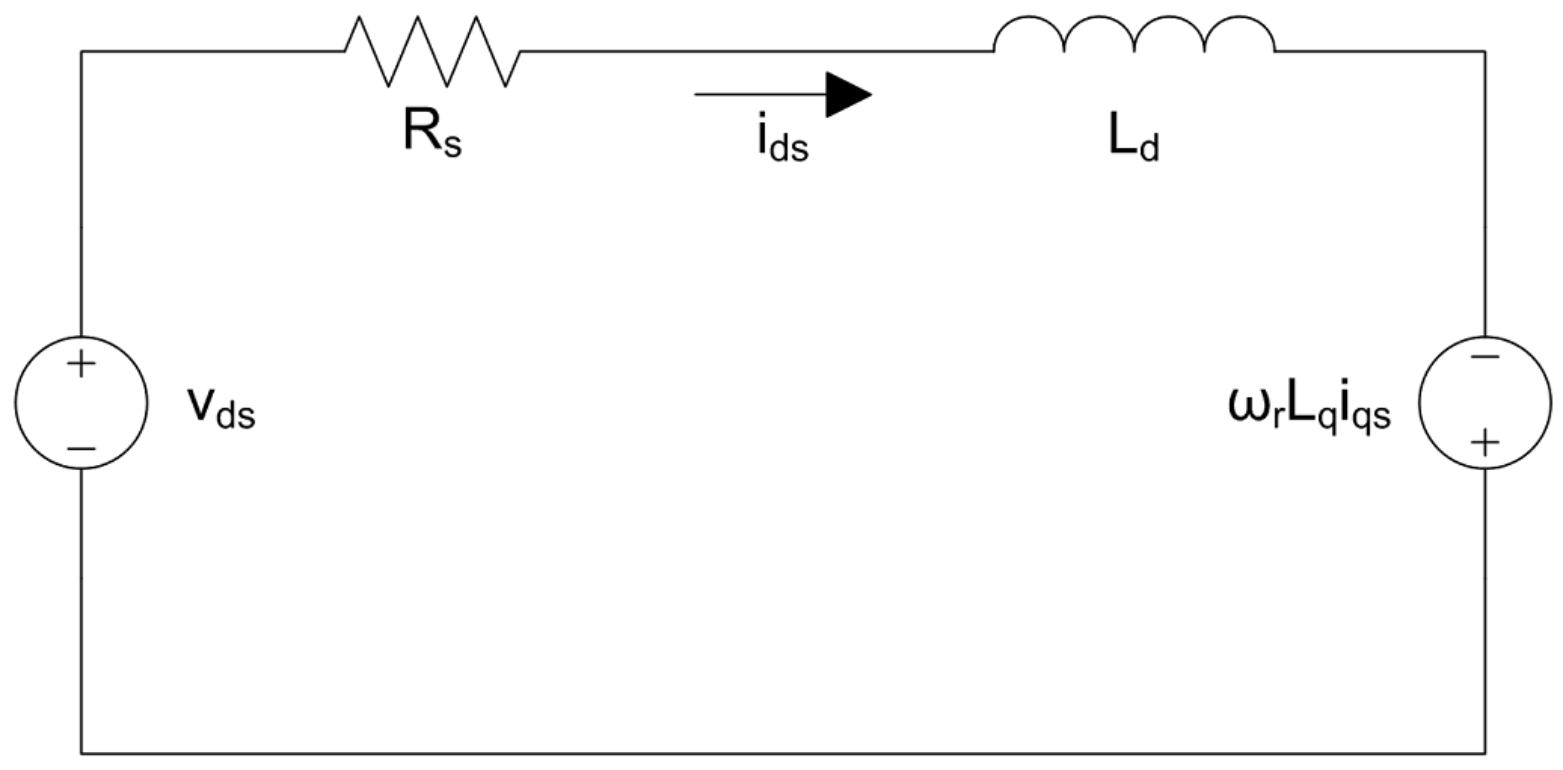

Figure 5 - PMSM and OWPMSM d-axis equivalent circuit

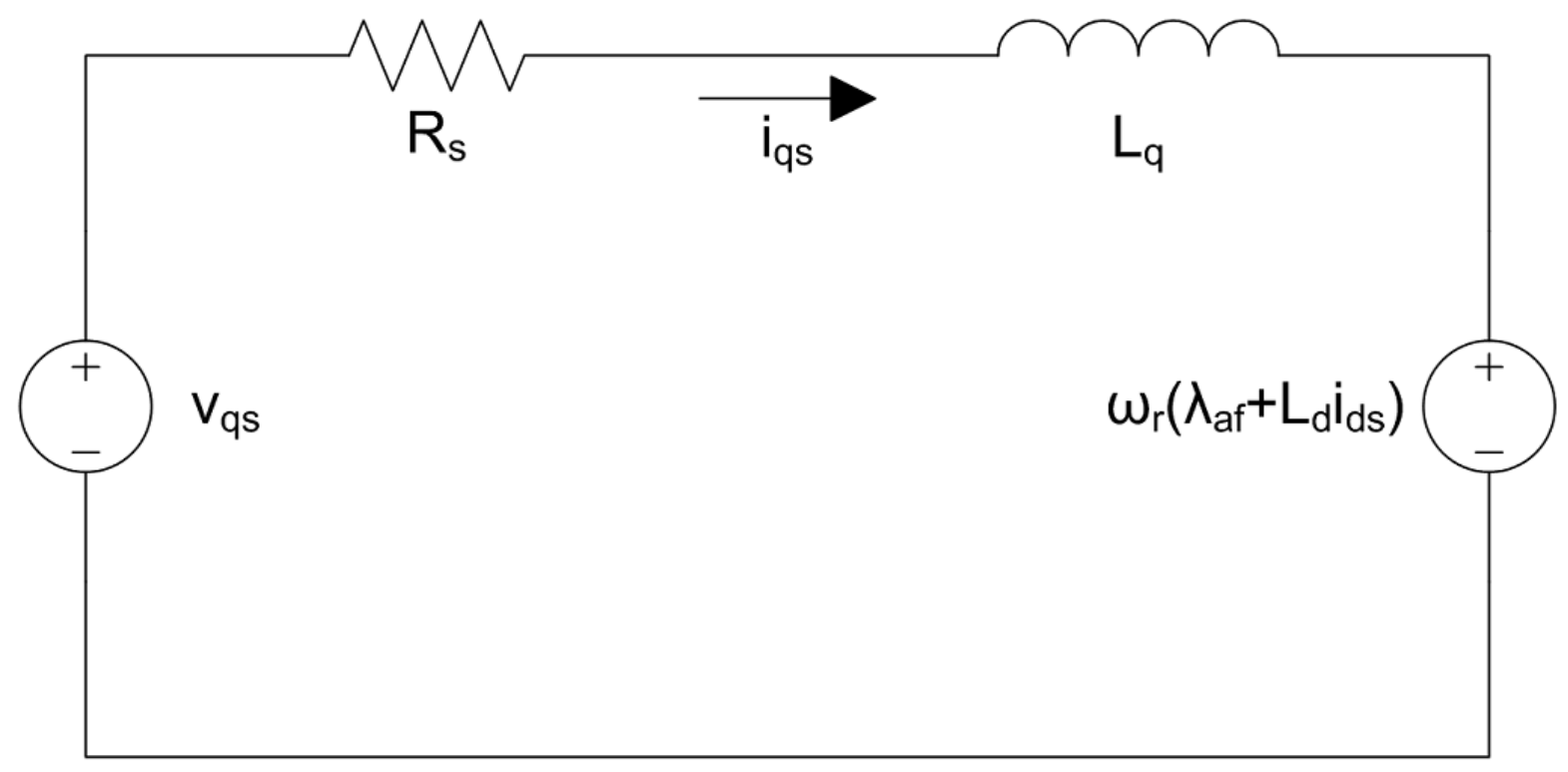

Figure 6 - PMSM and OWPMSM q-axis equivalent circuit 


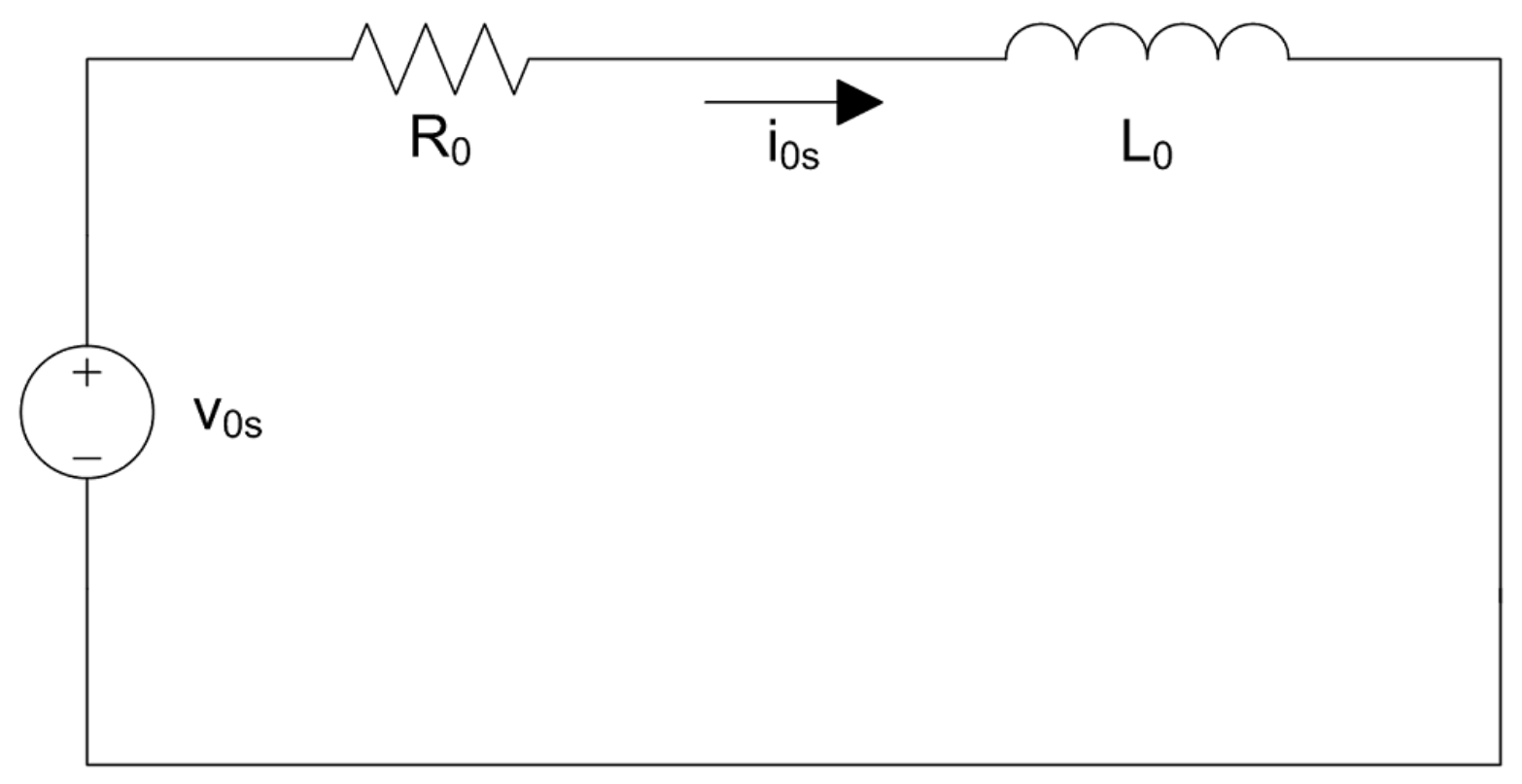

Figure 7 - PMSM and OWPMSM 0-axis equivalent circuit

Based off of these circuit equations, [1] derives a slightly simplified dynamic model for the OWPMSM assuming symmetrical terminal voltages with no DC offset and equal ground potentials for the primary and secondary inverters. Under these constraints, the author shows that the stator voltage of an OWPMSM in the rotor reference frame is equal to the difference of the inverter output voltages in the rotor reference frame, $v_{s 1}^{r}$ and $v_{s 2}^{r}$. In other words, using the secondary windings of the OWPMSM has the effect of adding a secondary DC source in series with, but with opposite polarity to, the primary source in the circuits from Figure 5 - Figure 7. Therefore, the dynamic model of the stator windings and rotor are identical to those of a PMSM. The only difference between the two motor models is the method in which the stator voltage is applied to the windings. This implies, as expected, that an OWPMSM with the secondary terminals shorted together generally behaves identically to a PMSM. (2-18) - (2-20) quantify this effect when ignoring zero-sequence current. Now, (2-16) and (2-17) model the power, torque and speed of OWPMSM based on the stator voltage as expressed in (2-18). 


$$
\begin{gathered}
v_{d q s}^{r}=v_{d q s 1}^{r}-v_{d q s 2}^{r} \\
v_{d s}^{r}=v_{d s 1}^{r}-v_{d s 2}^{r}=R_{s} i_{d s}^{r}+L_{d} \frac{d i_{d s}^{r}}{d t}-\omega_{r} L_{q} i_{q s}^{r} \\
v_{q s}^{r}=v_{q s 1}^{r}-v_{q s 2}^{r}=R_{s} i_{d s}^{r}+L_{q} \frac{d i_{q s}^{r}}{d t}+\omega_{r}\left(L_{d} i_{d s}^{r}+\lambda_{a f}\right)
\end{gathered}
$$

The relationship between stator inductances can divide permanent magnet-based motors broadly into two categories: salient pole and nonsalient pole motors. In nonsalient pole motors, the stator inductance does not vary with time, so $L_{d}=L_{q}$. Surface-mounted permanent-magnet (SPM) motors, where magnets are attached to the surface of the rotor, are typically salient pole machines. On the other hand, the stator inductance do vary over time in salient pole motors, so $L_{d} \neq L_{q}$. Interior permanent-magnet (IPM) motors, where the magnets are embedded within the rotor, are typically nonsalient pole motors. Two factors limit the speed range of SPM motors: the strength of the adhesive used to attach the magnets to the motor and the speed range of motor drive. On the other hand, IPM motors are typically only limited by the speed range of the drive. Therefore, IPM motors typically can achieve higher speeds and are used more often in EVs [2]. While the types of control described in the following sections can generally apply to both types of motors, the specific equations used to implement the control are derived for IPM machines, so they may need to be slightly altered based on asymptotic behavior when $L_{d}=L_{q}$.

\subsection{Control of a Permanent Magnet-Based Motor}

Equations (2-17),(2-19), and (2-20) are fundamental equations for permanent magnet motor drive theory [7]. The last terms of (2-19) and (2-20) shows that the flux produced by $i_{d s}^{r}$ is 
in phase with the rotor flux, $\lambda_{a f}$. This flux induces a voltage in the windings that is in-phase with the back EMF, $E_{i}^{r}$, and that grows linearly with speed like the back EMF. Because of this, the daxis current, $i_{d s}^{r}$, is said to control the flux in the rotor. Similarly, the difference between $L_{d}$ and $L_{q}$ will be either small or zero for most machines, so according to (2-17), $i_{q S}^{r}$ will have a significant effect on torque production while $i_{d s}^{r}$ has a minimal effect. For this reason, the q-axis current, $i_{q S}^{r}$, is said to control the torque.

From the rotor reference frame mathematical model in (2-17),(2-19), and (2-20) come the state space equations in (2-21) - (2-24), which completely describe the states of the system $\left(i_{d s}^{r}\right.$, $i_{q s}^{r}, \theta_{r}$, and $\left.\omega_{r}\right)$ for any input $\left(v_{d s}^{r}, v_{q s}^{r}, T_{l}\right)$ [7]. Again, for the dual inverter drive, the stator voltage components $v_{d s}^{r}$ and $v_{q s}^{r}$ are determined by (2-18).

$$
\begin{gathered}
\frac{d i_{d s}^{r}}{d t}=\frac{1}{L_{d}}\left[\left(-R_{s}+\omega_{r} L_{q}\right) i_{d s}^{r}+v_{d s}^{r}\right] \\
\frac{d i_{q s}^{r}}{d t}=\frac{1}{L_{q}}\left[\left(-R_{s}-\omega_{r} L_{d}\right) i_{q s}^{r}-\omega_{r} \lambda_{a f}+v_{q s}^{r}\right] \\
\frac{d \omega_{r}}{d t}=\frac{2}{P} \frac{1}{J}\left(T_{e}-T_{l}\right)-B \omega_{r} \\
\frac{d \theta_{r}}{d t}=\omega_{r}
\end{gathered}
$$

Figure 8 shows a typical control block diagram for a PMSM motor drive, and Sections 2.2.1 - 2.2.3 explain the details of each of these control blocks. Section 2.2.1 explains the first and last blocks of the control loop: speed and current regulation using PI control. Section 2.2.2 explores the process for finding the optimal ratio of $i_{d s}^{r}$ and $i_{q s}^{r}$ for torque production for any combination of $L_{d}$ and $L_{q}$, called MTPA control. Controllers typically employ this type of control when the drive can supply enough voltage to oppose the induced back EMF at the desired speed while 
inducing enough current in the stator windings to produce the desired torque. Section 2.2.3 explores the use of $i_{d s}^{r}$ to weaken the amount of the flux linkage in the stator windings, called flux weakening control. Drives typically use this type of control at high speeds when it cannot supply enough voltage to oppose the back EMF generated at high speeds.

The presented control laws often use a normalized, per unit system to simplify calculations. Typically, PMSM systems are normalized according to the method described in [7]. Under these conditions, the normalized torque, $T_{e n}$, and normalized stator current magnitude, $i_{s n}$, are equal, and the base speed is $1 \mathrm{pu}$. By convention, the controllers in Figure 8 use MTPA control below base speed and flux weakening control above, in which case the drive should supply maximum voltage to the stator at and above base speed.

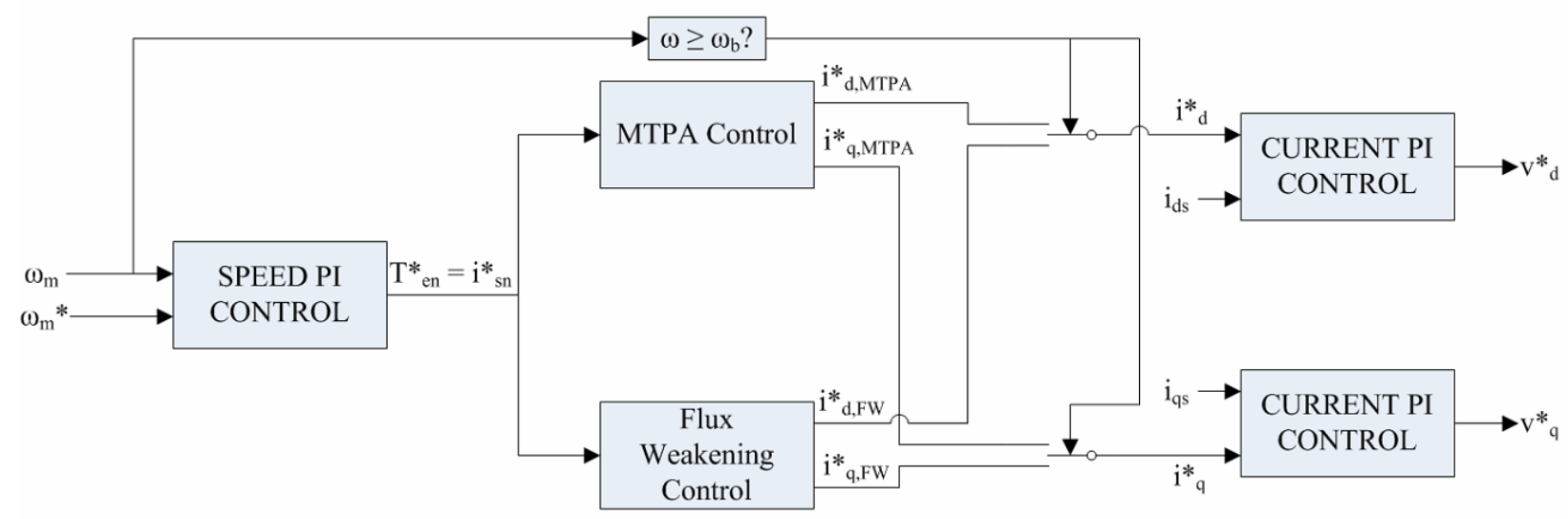

Figure 8 - Typical Control Block Diagram for PMSM Drives

\subsubsection{Speed and Current Control}

According to Newton's Second Law for Rotation and shown in (2-23), torque production controls the speed of the motor, and according to (2-17), the stator current controls the electromagnetic torque production in the motor for a given input. Therefore, the controller must 
regulate the stator current to regulate the electromagnetic torque, and hence the motor speed. As explained in [17], PI controllers can accomplish this, despite the nonlinearities of the system, by making the time constant of the speed control loop (i.e. the outer loop) sufficiently larger than the time constant of the current control loop (i.e. the inner loop). This section explains the procedure for accomplishing this from [17].

Define the current loop bandwidth, $\omega_{c c}$, to be 10-20 times less than the switching frequency of the inverter, $\omega_{s w}$, and the speed loop bandwidth, $\omega_{c s}$, to be 5-10 times less than the $\omega_{c c}$. Then, $(2-25)-(2-27)$ define the PI controller for the speed loop, where $J$ is the moment of inertia of the motor, $\lambda_{a f}$ is the permanent magnet flux linkage, and a superscript "*" denotes a reference value for the controller, and a subscript "n" denotes a normalized value.

$$
\begin{gathered}
K_{p s}=\frac{J \omega_{c s}}{\lambda_{a f}} \\
K_{i s}=\frac{J \omega_{c s}}{5 \lambda_{a f}} \\
T_{e n}^{*}=i_{s n}^{*}=K_{p s}\left(\omega_{m n}^{*}-\omega_{m n}\right)+K_{i s} \int\left(\omega_{m n}^{*}-\omega_{m n}\right)
\end{gathered}
$$

As suggest by the different branches of the control block diagram in Figure 8, different methods exist for separating $i_{s n}^{*}$ into components $i_{d s n}^{*}$ and $i_{q s n}^{*}$, and the following sections will explain two popular algorithms (MTPA and flux weakening). Given these values, (2-28) - (2-34) represent PI controllers that regulate the stator current by changing the $\mathrm{d}$ - and q-axis stator voltages, $v_{d s}^{r}$ and $v_{q s}^{r}$. Including the feedforward terms, $v_{d s, f f}^{*}$ and $v_{q s, f f}^{*}$, decouples the two current loops to improve the dynamic performance [17]. Note that the following equations apply only to a nonsalient pole machines but can be adapted to work with salient pole machines by using different values for $K_{p c}$ according to the values of $L_{d}$ and $L_{q}$. 


$$
\begin{gathered}
K_{p c d}=L_{d} \omega_{c c} \\
K_{p c q}=L_{q} \omega_{c c} \\
K_{i c}=R_{s} \omega_{c s} \\
v_{d s, f f}^{*}=-\omega_{r} L_{q} i_{q s}^{r} \\
v_{q s, f f}^{*}=\omega_{r}\left(L_{d} i_{d s}^{r}+\lambda_{a f}\right) \\
v_{d s}^{*}=K_{p c d}\left(i_{d s}^{*}-i_{d s}^{r}\right)+K_{p i} \int\left(i_{d s}^{*}-i_{d s}^{r}\right)+v_{d s, f f}^{*} \\
v_{q s}^{*}=K_{p c q}\left(i_{q s}^{*}-i_{q s}^{r}\right)+K_{p i} \int\left(i_{q s}^{*}-i_{q s}^{r}\right)+v_{q s, f f}^{*}
\end{gathered}
$$

\subsubsection{MTPA Control - Below Base Speed}

MTPA control aims to maximize torque production for a given magnitude of stator current by distributing current along the $\mathrm{d}$ - and q-axes in such a way that maximizes (2-17). In other words, MTPA control varies the angle of the stator current space vector with respect to the d-axis, $\delta$, to maximize torque production [7]. To solve for the required $\delta$, substitute identities for $i_{d s}^{r}$ and $i_{q s}^{r}$ from (2-35) into (2-17), and normalize to obtain (2-36). For a nonsalient pole machine, the

resulting expression is simple, and the angle $\delta=\frac{\pi}{2}$ obviously maximizes torque production. However, MTPA control of salient pole permanent magnet motors requires more rigorous analysis. Taking the derivative of $T_{e n}$ in (2-36) with respect to $\delta$, setting the result equal to zero, and solving for $\delta$ to obtains an expression for the current angle that maximizes torque production, shown in $(2-37)$.

$$
\begin{gathered}
{\left[\begin{array}{l}
i_{d s}^{r} \\
i_{q s}^{r}
\end{array}\right]=i_{s n}^{r}\left[\begin{array}{l}
\cos (\delta) \\
\sin (\delta)
\end{array}\right]} \\
\rightarrow T_{e n}=i_{s n}\left[\lambda_{a f, n} \sin (\delta)+\frac{1}{2}\left(L_{d n}-L_{q n}\right) i_{s n} \sin (2 \delta)\right] \\
\rightarrow \delta=\cos ^{-1}\left\{-\frac{\lambda_{a f, n}}{4\left(L_{d n}-L_{q n}\right) i_{s n}}+\sqrt{\left(\frac{\lambda_{a f, n}}{4\left(L_{d n}-L_{q n}\right) i_{s n}}\right)^{2}+\frac{1}{2}}\right\}
\end{gathered}
$$


Because the speed control loop from the previous section determines the stator current magnitude reference, $i_{s n}^{*}$, achieving the $\delta$ described by (2-37) is the only necessary condition for achieving MTPA control. Hence, "the MTPA condition" hereto refers to the angle $\delta$ described by (2-37). The motor drive can satisfy this condition as long as the inverter is capable of supplying the resultant voltage references generated the PI controller described by (2-33) and (2-34). This is ideally possible for all speeds less than $1 \mathrm{pu}$, or base speed.

\subsubsection{Flux Weakening Control - Above Base Speed}

At high speeds, the motor drive cannot supply the required voltage to satisfy the MTPA condition, so instead flux weakening control diverts extra current to the d-axis in order to weaken the effect of the rotor flux while the drive supplies maximum voltage at all speeds. Doing so decreases available torque. In order to simplify calculations, flux weakening control, as described in [7], ignores the effects of rotor resistance. This is reasonable because flux weakening control is typically only used at high speeds, when the speed-dependent terms dominate the expression for voltage in (2-19) and (2-20). Then, the following equations describe the normalized steady state voltage.

$$
\begin{gathered}
v_{d s}^{r}=\omega_{r} L_{q n} i_{q s n}^{r} \\
v_{q s}^{r}=\omega_{r}\left(\lambda_{a f n}+L_{d n} i_{d s n}^{r}\right) \\
\boldsymbol{v}_{\boldsymbol{s n}}^{2}=\boldsymbol{\omega}_{\boldsymbol{r n}}^{2}\left[\left(\lambda_{\boldsymbol{a f n}}+\boldsymbol{L}_{\boldsymbol{d n}} \boldsymbol{i}_{\boldsymbol{d s n}}^{r}\right)^{2}+\left(\boldsymbol{L}_{\boldsymbol{q} \boldsymbol{n}} \boldsymbol{i}_{\boldsymbol{q} \boldsymbol{s} \boldsymbol{r}}^{r}\right)^{2}\right]
\end{gathered}
$$

Substituting the identity for $i_{q S n}^{r}$ from (2-39) into (2-38) leads to a quadratic equation for $i_{d s n}^{r}$ in (2-40). Because the desired value of $\omega_{r n}$ is known based on the operating condition, the 
speed PI regulator determines the reference for $i_{s n}$, and the desired value for $v_{s n}$ is known to be 1 based on the operating conditions of this type of control, the values of $a, b$, and $c$ will be known. (2-40) solves for the desired $i_{d s n}^{*}$ based on those conditions. Substituting this value back into (2-39) yields a maximum value for $i_{q s n}^{r}$ in (2-41).

$$
\begin{aligned}
& i_{q s n}^{r}=\sqrt{i_{s n}^{r 2}-i_{d s n}^{r 2}} \\
& v_{s n}^{2}=V_{M A X}^{2}=\omega_{r n}^{2}\left\{L_{q n}^{2}\left(i_{s n}^{2}-i_{d s n}^{r}{ }^{2}\right)+\left(\lambda_{a f n}+L_{d n} i_{d s n}^{r}\right)^{2}\right\} \\
& 0=a\left(i_{d s n}^{r}\right)^{2}+b i_{d s n}^{r}+c \\
& a=L_{d n}^{2}-L_{q n}^{2} \\
& b=2 \lambda_{a f n} L_{d n} \\
& c=\lambda_{a f n}^{2}+L_{q n}^{2} i_{s n}^{2}-\left(\frac{1}{\omega_{m n}}\right)^{2} \\
& i_{d s n}^{*}=\left\{\begin{aligned}
-\frac{c}{b}, & L_{d}=L_{q} \\
\frac{-b+\sqrt{b^{2}-4 a c}}{2 a}, & L_{q} \neq L_{q}
\end{aligned}\right. \\
& i_{q s n, M A X}^{r}=\sqrt{i_{s n}^{r^{2}-i_{d s n}^{*}{ }^{2}}}
\end{aligned}
$$

This combination of $\mathrm{d}$ - and q-axis current will give the maximum possible torque at that speed, $T_{e n, M A X}$, according to (2-42), obtained by normalizing (2-17). Thus, the reference torque, $T_{e n}^{*}$, will equal the torque commanded by the speed controller, $T_{e c}$, only if it is less than this maximum value according to (2-43). Using this value, (2-44) gives an expression for commanded q axis current $i_{q s n}^{*}$, also based on (2-17).

$$
\begin{gathered}
T_{e n, M A X}=i_{q s n, M A X}^{r}\left(\lambda_{a f, n}+\left(L_{d n}-L_{q n}\right) i_{d s n}^{*}\right) \\
T_{e n}^{*}=\min \left(T_{e n, \max }, T_{e c}\right) \\
i_{q s n}^{*}=\frac{T_{e n}^{*}}{\lambda_{a f, n}+\left(L_{d n}-L_{q n}\right) i_{d s n}^{*}}
\end{gathered}
$$


The maximum speed for flux weakening control occurs when all of the stator current flows on the d-axis. Thus, there is no q-axis current, and therefore no torque production above that speed. Using this intuition, [7] solves for the maximum normalized speed with flux weakening control, shown in (2-45), by first normalizing (2-15) and then taking the magnitude of the stator voltage while neglecting the 0 -axis.

$$
\omega_{M A X, F W}=\frac{\sqrt{1-R_{s n}^{2}}}{\lambda_{a f n}-L_{d n}} p u
$$

\subsection{Relevant PMSM Motor Drives from Literature}

While identical mathematical models describe a PMSM and OWPMSM, different power electronic topologies can drive each type motor, if desired. While a conventional topology in Figure 1 can drive both motors (i.e. by shorting the secondary windings of the OWPMSM), the dual inverter drive is only available to the OWPMSM. Fundamentally, both types of drives convert $\mathrm{DC}$ power to $\mathrm{AC}$, and in the context of battery-powered $\mathrm{EVs}$, they must be bidirectional in order to facilitate regenerative breaking. However, a conventional drive uses a single voltage source inverter (VSI) to implement the DC/AC conversion and includes a bidirectional DC/DC.

Alternatively, Figure 2 shows the dual inverter drive associated with OWPMSMs. Compared to a conventional motor drive, the dual inverter drive uses two VSIs to apply different voltages of each set of three-phase terminals. These drives can use a single, shared voltage source, two independent voltage sources, or a voltage source and floating capacitor to supply the DC link voltages in this type of drive. This type of drive has attracted attention more recently for EVs because of its ability to highly integrate three-phase AC and DC fast chargers into the drivetrain 
[12], [13]. [13] shows that this type of drive can adequately control the battery current during charging, so literature often does not include the boost converter module found in conventional EV motor drives to reduce the component count and complexity of the drive. However, doing so ignores the other benefits of including the DC/DC converter module, explained in the following paragraphs, that have already proven to be true for a PMSM and conventional motor drive [4].

Arguably, the most important function of the DC/DC converter is to enable regenerative breaking while protecting the health of the battery [14]. However, [6] and [15] show how this DC/DC stage can be utilized during driving to improve the performance of the drive. [6] shows that boosting the DC link voltage can extend the speed range of a conventional drive while maintaining the MTPA condition at all operating points. Moreover, by limiting the battery current to mimic the constant power behavior, the controller must buck the stator current to boost the voltage. As a result, the torque also decreases as speed increases in a way that matches torque production when using flux weakening, but it requires less stator current to do so. Hence, [6] shows experimentally that the conduction losses in the motor are lower at high speeds compared to flux weakening control. Section 4.0 shows this to also be true in simulation for the proposed drive.

Despite the advantages proven in [6], the authors note that the DC/DC module adds nonnegligible conduction losses below base speed when implemented using Si IGBTs. This can pose problems in EVs because the efficiency of power electronic systems in EVs can significantly impact the size and weight of onboard thermal management systems and, as a result, vehicle range [4]. Luckily, [15] shows more recently that using $\mathrm{SiC}$ MOSFETs helps to alleviate this issue. It also shows experimentally that boosting the DC link voltage at high speeds improves inverter efficiency. However, the author did not have the resources to investigate this claim in the context of the proposed drive at the time of publishing this thesis. 
To further study the benefits of the DC/DC module in the context of a dual inverter drive, Section 3.0 proposes a topology and control scheme that can boost the DC link voltage at high speeds based off of the presented research for the conventional and dual inverter drives. Because all three drives (conventional, dual inverter, proposed) use the same common topologies to implement the boost converter and VSI modules, Sections 2.3.1 and 2.3.2 reviews these topologies and ways to control them.

\subsubsection{Synchronous Boost Converter}

Because of its popularity in EV drives due to simplicity and bidirectionality [4], this work uses the synchronous boost converter to implement the DC/DC module, shown in Figure 9. [18] explains the operation of this circuit. In summary, Switches S1 and S2 have inverse switching signals - when S1 is closed, S2 is open, and vice versa. When S1 is closed, the amount of energy stored in the inductor increases as the inductor charges (i.e. the inductor current increases). At the same time, $\mathrm{S} 2$ is open, so the capacitor solely powers the output, decreasing the amount of energy stored in the capacitor (i.e. the capacitor voltage decreases). On the other hand, when S1 is open and, therefore, $\mathrm{S} 2$ is closed, power still flows from the input to the output, despite the negative voltage across the inductor, because of the inductor current inertia. The excess current from the inductor then charges the capacitor. Hence, this switching action transfers energy from the inductor to the capacitor as the inductor discharges and the capacitor charges. Therefore, in this topology, the inductor and capacitor represent energy storage elements along with filtering elements. As a result, when the inductor current increases, the capacitor voltage decreases, and vice versa. 


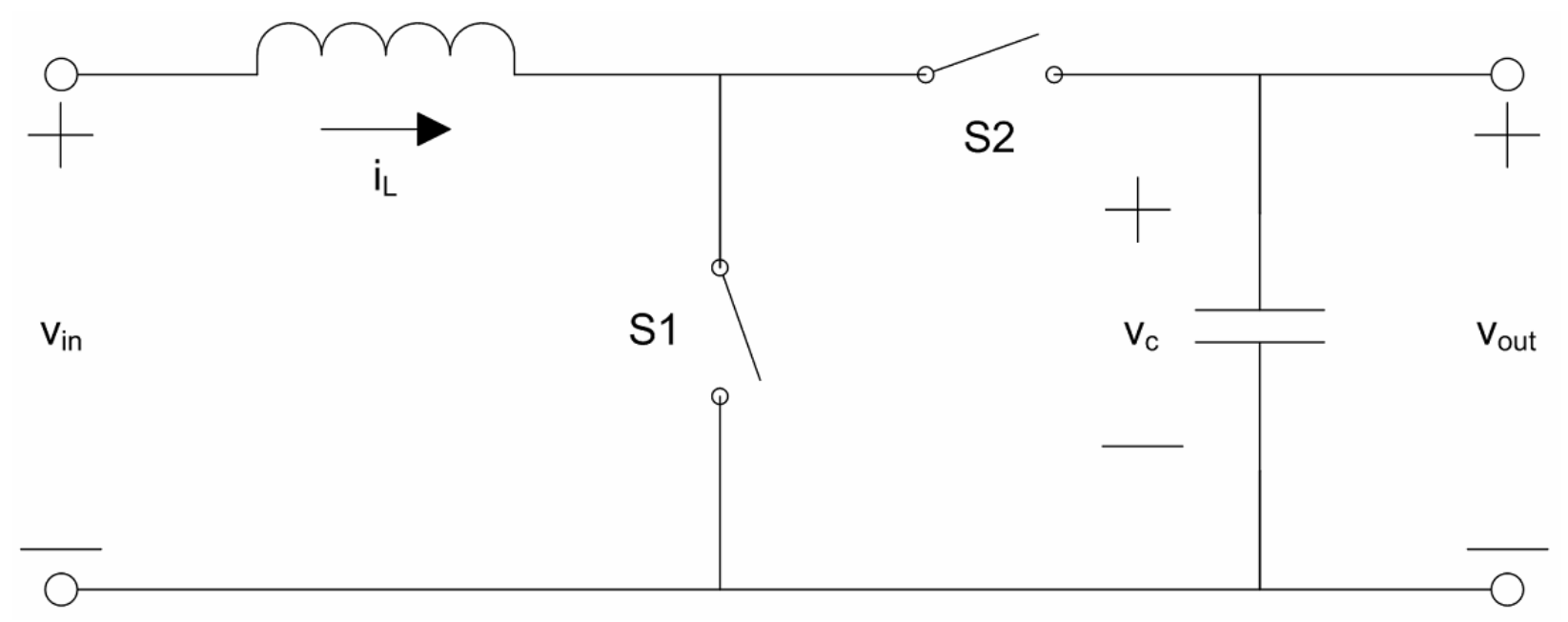

Figure 9 - Synchronous Boost Converter

This type of boost converter is a nonminimum phase (NMP) system [19]. NMP systems introduce a potentially destabilizing right-hand plane (RHP) zero that complicates the control compared to minimum phase (MP) systems, such as a buck converter. Consequently, while PI control can effectively regulate the output voltage of a buck converter, it is difficult to do so for boost converter with a high inductance, heavy load, and/or a high voltage gain because these three conditions move the RHP zero closer to the imaginary axis [20]. These operating conditions, which are common in motor drives, require the use of nonlinear controllers.

This work uses hysteresis control, a type of nonlinear control, to regulate the output voltage of the synchronous boost converter. As described in [19], hysteresis control defines switching boundaries based off of the boost converter equilibrium points to regulate the output voltage. When the state of the system crosses the switching boundary, S1 and S2 invert states. To understand this first consider the switched model of the boost converter states, shown in (2-46) and (2-47). Here, $q$ represents the switching function, with a value of 1 when $\mathrm{S} 1$ is closed (S2 is open) and 0 when $\mathrm{S} 1$ is open (S2 is closed), and $q^{\prime}$ represents the inverse of the switching function. Based off of the 
switching function, two possible equilibrium points exist for this system: $x_{01}$ for $q=1$ and $x_{02}$ for $q=0$. (2-49) gives the value for $x_{02}$. However, as shown in (2-48), $x_{01}$ does not exist because the inductor current grows without bound as a result of the voltage applied across the inductor.

$$
\begin{gathered}
x=\left[\begin{array}{l}
x_{1} \\
x_{2}
\end{array}\right]=\left[\begin{array}{l}
i_{L} \\
v_{C}
\end{array}\right] \\
\left\{\begin{array}{l}
L \dot{x_{1}}=v_{\text {in }}-q^{\prime} x_{2} \\
C \dot{x_{2}}=q^{\prime} x_{1}-i_{o u t}
\end{array}=\left\{\begin{array}{c}
L \dot{x}_{1}=v_{\text {in }}-q^{\prime} x_{2} \\
C \dot{x_{2}}=q^{\prime} x_{1}-\frac{P_{o u t}}{x_{2}}
\end{array}\right.\right. \\
x_{01} \rightarrow\left[\begin{array}{l}
\infty \\
0
\end{array}\right] \\
x_{02}=\left[\begin{array}{c}
i_{o u t} \\
v_{\text {in }}
\end{array}\right]=\left[\begin{array}{l}
P_{o u t} \\
v_{\text {in }} \\
v_{\text {in }}
\end{array}\right]
\end{gathered}
$$

Now, consider the following heuristics for selecting a switching boundary [19]:

1. The equilibrium points must lie on opposite sides of the switching boundary.

2. The switching must prevent the system from reaching an equilibrium point.

3. The regulated state variable must change as a direct result of the switching action.

4. To avoid excessively fast switching ("chattering"), surround the switching boundary with a dead band. If the operating point is within the dead band, the switch state should not change, even if it has crossed the switching boundary. The switch state should only change when the operating point crosses the switching boundary and leaves the dead band.

5. The dead band must include the desired operating point.

According to these heuristics, hysteresis control cannot directly regulate the output voltage of the synchronous boost converter. For example, the operating range is, by definition, $x_{2}=$ $v_{\text {out }} \geq v_{\text {in }}$, so according to (2-48) and (2-49), no switching boundary can satisfy both heuristic 1 
and 5. Alternatively, the equilibrium points for the inductor current comprise the entire operating range of the converter. The inductor current of the first equilibrium point represents the theoretical maximum, and that of the second represents the current required to produce the minimum output voltage, $v_{\text {out }}=v_{\text {in }}$, for a given output power. Given a constant input voltage and a commanded output current, as expected in an EV motor drive, increasing the output voltage beyond the minimum value requires increasing the inductor current according to the conservation of power principle. As a result, the second equilibrium point represents the minimum value for the inductor current. Because of this, hysteresis control of the inductor current can regulate the output voltage if given information regarding the amount of inductor current required to produce a desired output voltage.

\subsubsection{Two-level, Three-phase Voltage Source Inverter (VSI)}

Also due to its popularity in EV drives [4], the two-level, three-phase voltage source inverter, hereto referred to as a VSI, constitutes the DC/AC stage of the drives in this work. Figure 10 shows a schematic of the VSI. S1 and S1' switch inversely, using sinusoidal pulse width modulation (SPWM) or space vector modulation (SVM) for example, to apply a voltage pulses to the filter network in such a way that induces sinusoidal current in phase a. Similarly, S2 and S2' switch to induce current in phase b and, S3 and S3' do so for phase c. In the context of motor drives, the stator winding inductance and resistance can serve as the filtering network. 


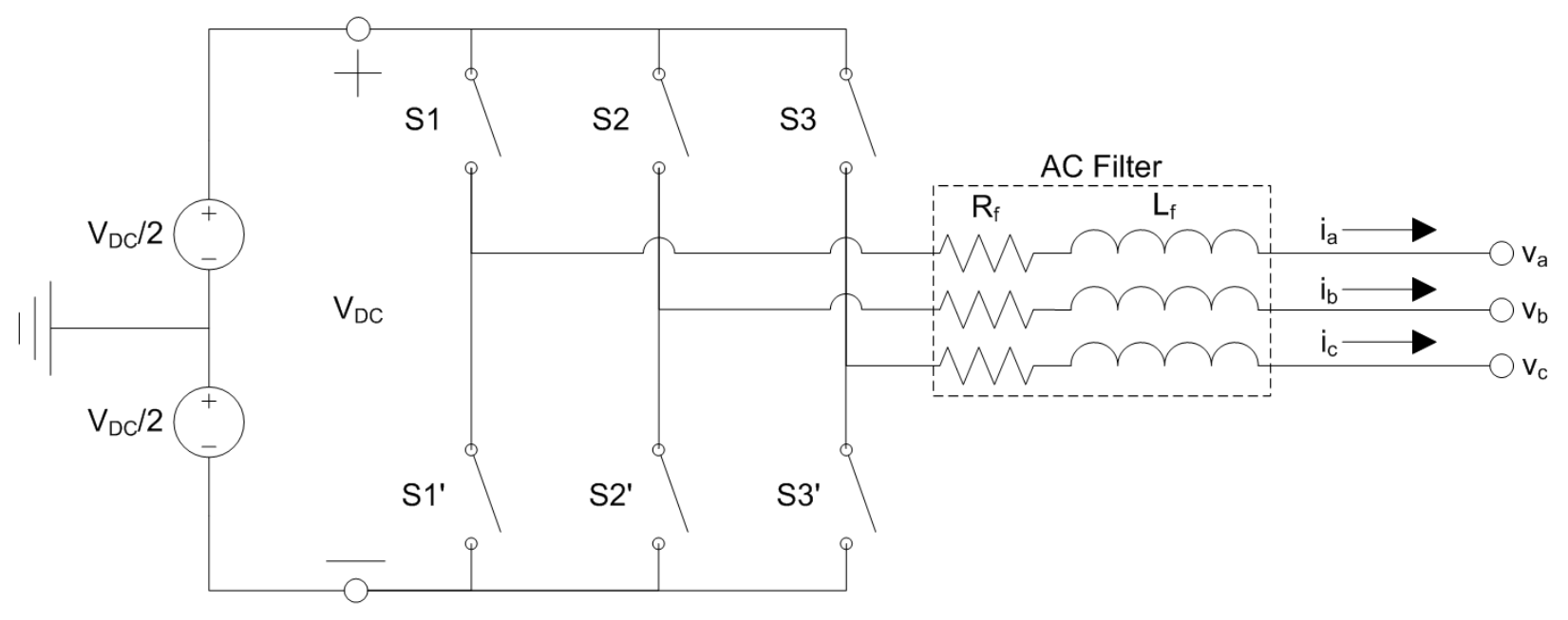

Figure 10 - Schematic of Two-Level, Three-phase Voltage Source Inverter

The pulses will either have values between $\frac{V_{D C}}{2}$ and $-\frac{V_{D C}}{2}$. Based on the Fourier analysis of the modulation signal, the maximum magnitude of the fundamental voltage component without overmodulating (i.e. adding undesirable harmonics) is $\frac{V_{D C}}{2}$ using SPWM and $1.15 \frac{V_{D C}}{2}$ using SVM. See [16] for further explanation of the operation of the VSI. To increase the output voltage magnitude beyond this point without overmodulating, the DC/DC converter must boost the DC link voltage.

As per Figure 2, the speed controller sends a voltage reference in the dq-frame to the VSI. When using SPWM, the VSI controller simply transforms the reference voltage to the abc-frame using (2-10) - (2-12). The signals in the abc-frame are then used as the modulation signal for each phase. A triangle wave is typically used as the carrier signal. When the modulation signal is greater than the carrier signal, the switching network applies a positive voltage to that phase. On the other hand, when the modulation signal is greater, a negative voltage is applied to that phase.

An alternative modulation scheme, SVM, minimizes the number of switching actions required and lowers the total harmonic distortion (THD) of the output in doing so [19]. Figure 11 
shows the voltage space vector states for a single inverter $\left(V_{0}\right.$ through $\left.V_{7}\right)$. In this case, the dq-axes are stationary and are included only as an angle reference. Converting the subscript to a binary value translates to the gate signals for $S_{1}, S_{2}$ and $S_{3}$ used to obtain that space vector output pointing to that state (e.g. $V_{2}$ corresponds to $S_{1}=0, S_{2}=1$, and $S_{3}=0$ because $2_{10}=010_{2}$ ). Note that because of this, $V_{0}$ and $V_{7}$ are so-called "zero-states", where the output voltage space vector is the zero vector. These voltage states form the vertices of a hexagon, the zero-states being the center of said hexagon. Each voltage state is a distance $\frac{V_{D C}}{2}$ from the nearest adjacent states, and a VSI can generate any voltage space vector that points from the origin to some point within a circle of radius $1.15 \frac{V_{D C}}{2}$ when using $S V M$.

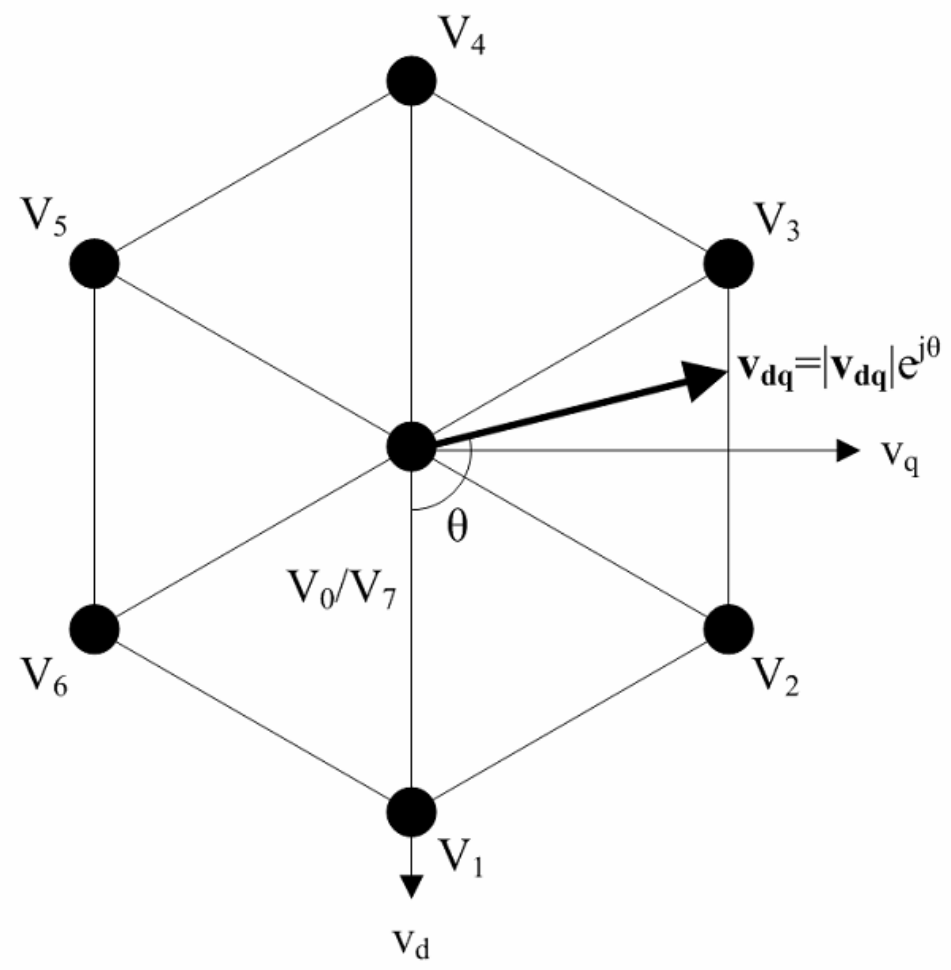

Figure 11 - VSI Space Vector States 
By extension, Figure 12 and Figure 13 shows the voltage space vector combinations of a dual inverter drive with different DC link voltages, obtained by superimposing the space vector hexagon of the secondary inverter over each space vector state of the primary inverter [1]. Figure 12 does so for a dual inverter drive with equal DC link voltages and Figure 13 for unequal DC link voltages (assuming $V_{D C 1} \geq V_{D C 2}$ ). The former has a greater output voltage range for a given primary DC link voltage, but the later produces less THD. By inspection, the voltage space vector states are equal to those of a multilevel inverter and therefore produce similar output voltages [1]. While this work uses SPWM to generate a modulation signal, these space vector states are used to decompose the stator voltage reference into refences for each inverter, explained in Section 3.1.3. 


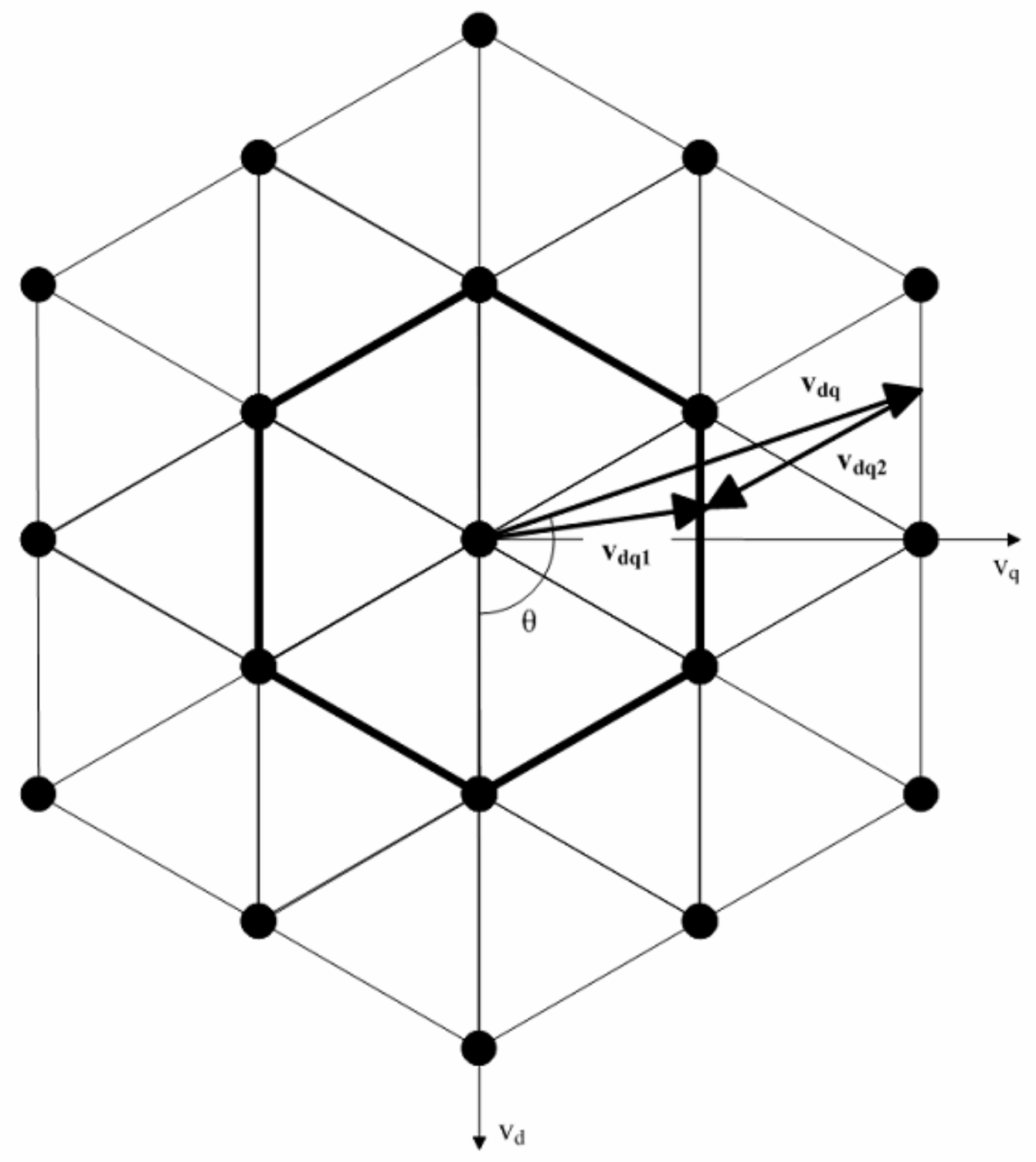

Figure 12 - Dual Inverter Drive Space Vector States: $V_{D C 1}=V_{D C 2}$ 


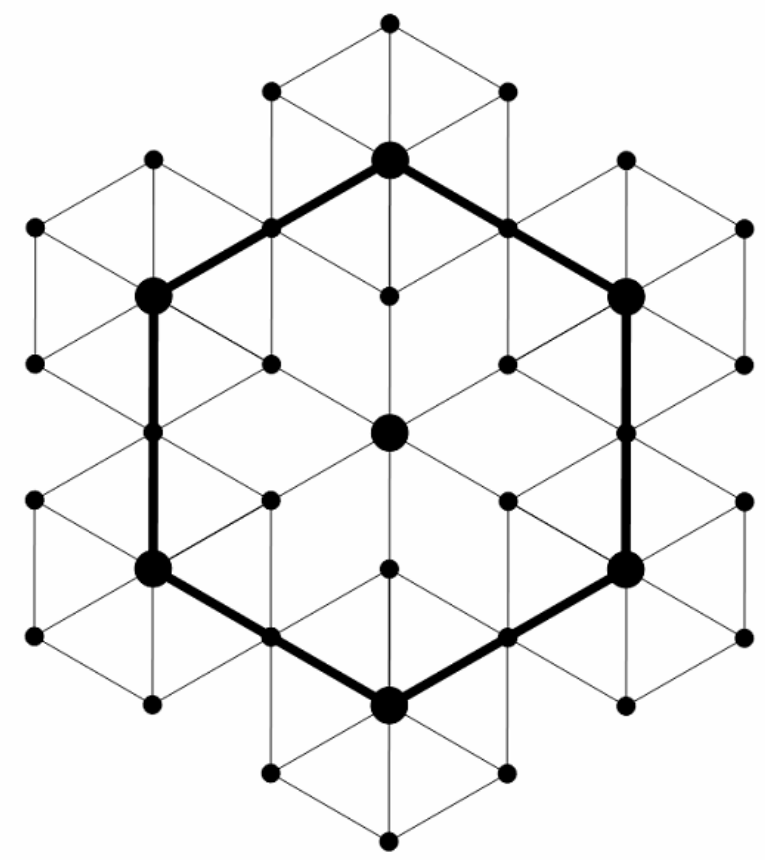

Figure 13 - Dual Inverter Drive Space Vector States: $V_{D C 1}=2 V_{D C 2}$ 


\subsection{Proposed OWPMSM Motor Drive with Boost Converter Modules}

This section explains the speed control for a dual inverter drive with a boost converter module that can increase the DC link voltage at high speeds to extend the operating range. This facilitates the use of lighter, more power dense motors [4], a notable advantage for EV applications due to the sensitivity of vehicle range to onboard weight [10]. Furthermore, the proposed control scheme reduces conduction losses in the motor compared to flux weakening control.

Using the model for the motor and the power electronic modules described in the previous section, Figure 14 represents a block diagram of the proposed topology and controller. Rationale for steps 1, 2, and 4 are based on established control for a conventional drive, while that of step 3 relates to the dual inverter drive. The following subsections explain the control laws and compare theoretical motor performance for this topology to that of the dual inverter drive without the boost converter modules.

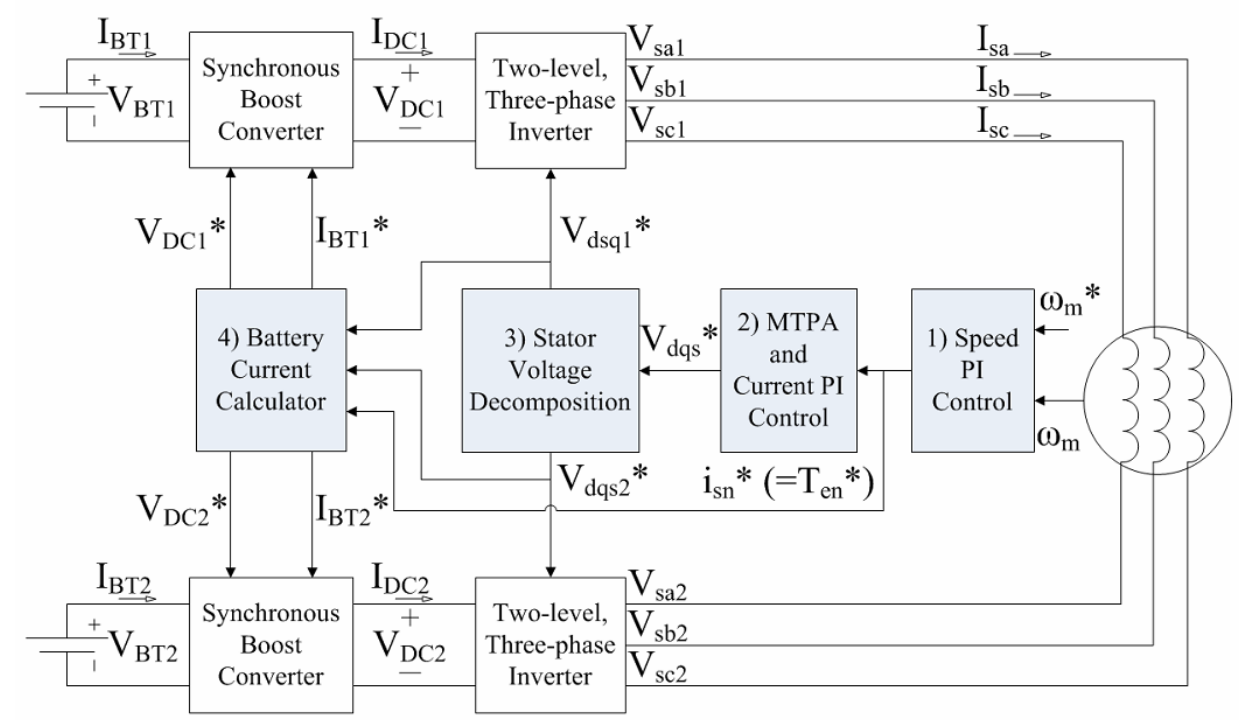

Figure 14 - Block Diagram of Dual Inverter Drive with Boost Converter Module 


\subsection{Theory of Operation}

The control algorithm depicted in Figure 14 can be separated into 4 key tasks: 1) determine the commanded torque and current based off of the rotor speed error using PI control, 2) determine the required stator voltage to reach the commanded torque and speed, as would be done with a PMSM, 3) separate the commanded stator voltage into two components, one for each power source, based upon the DC link voltages of each inverter, and 4) control the battery current to regulate the DC link voltage using hysteresis control.

\subsubsection{Task 1: Speed PI Control}

Because the OWPMSM and PMSM models for the stator windings are identical, the method for accomplishing the first task is identical to those used for a PMSM in Section 2.2.1. Thus, (2-25)-(2-27) describe the PI controller used in this topology to regulate the speed.

\subsubsection{Task 2: MTPA and Current PI Control}

Similarly, this topology adopts methods from the previous section for MTPA control and stator current regulation. However unlike in the previous section, MTPA control is possible at all available speeds and flux weakening control is unnecessary because the boost converter supplies additional voltage as needed to satisfy the MTPA condition. Now, the maximum allowable DC link voltage limits the speed range, instead of the angle of the stator current when using flux weakening control. Section 3.2 explains this comparison in more detail. 
To summarize this task, equations (2-35) and (2-37) determine the necessary $i_{d s}^{*}$ and $i_{q s}^{*}$ to satisfy the MTPA condition. Based off of these reference values, (2-28)-(2-34) describe the PI controllers used to generate stator voltage references, $v_{d s}^{*}$ and $v_{q s}^{*}$.

\subsubsection{Task 3: Stator Voltage Decomposition}

The goal of this task is to break the commanded stator voltage from Task $2, v_{d q s}^{*}$, into references for both inverters in the dual inverter drive, $v_{d q s 1}^{*}$ and $v_{d q s 2}^{*}$, based on the constraint of (2-18). The simplest method for doing so is to choose $v_{d q s 1}^{*}=-v_{d q s 2}^{*}=\frac{v_{d q s}^{*}}{2}$, but instead, this work adapts the method described for multilevel inverters in [21] to reduce switching losses and current total harmonic distortion (THD) when using SVM. This method relies on knowledge of the space vector states for the dual inverter drive described in Figure 11 - Figure 13 of Section 2.3.2.

To minimize switching losses, [21] forces $v_{d q s 1}^{*}$ to point exactly towards one of its voltage states at all times using (3-1)-(3-4). $\theta$ is the angle of the commanded stator voltage with respect to the direct axis, $\phi$ is the desired angle for the $v_{d q s 1}^{*}$, and $V_{D C 1}^{*}$ is the desired DC link voltage for the primary inverter. $s$ is the sector of the commanded voltage, illustrated in Figure 15. Each sector contains exactly one non-zero voltage space vector state of the primary VSI, and the sector number corresponds to the subscript of the voltage state for the primary inverter (i.e. for $s=2, v_{d q s 1}^{*}$ points to $\left.V_{2}\right)$. 


$$
\begin{gathered}
v_{d q s}^{*}=v_{d q s 1}^{*}-v_{d q s 2}^{*} \\
\theta=\tan ^{-1}\left(\frac{v_{d s}^{*}}{v_{q s}^{*}}\right) \\
s=\left(\left\lfloor\frac{\theta+30^{\circ}}{60^{\circ}}\right\rfloor \bmod 6\right)+1 \\
\phi=60^{\circ} *(s-1)
\end{gathered}
$$

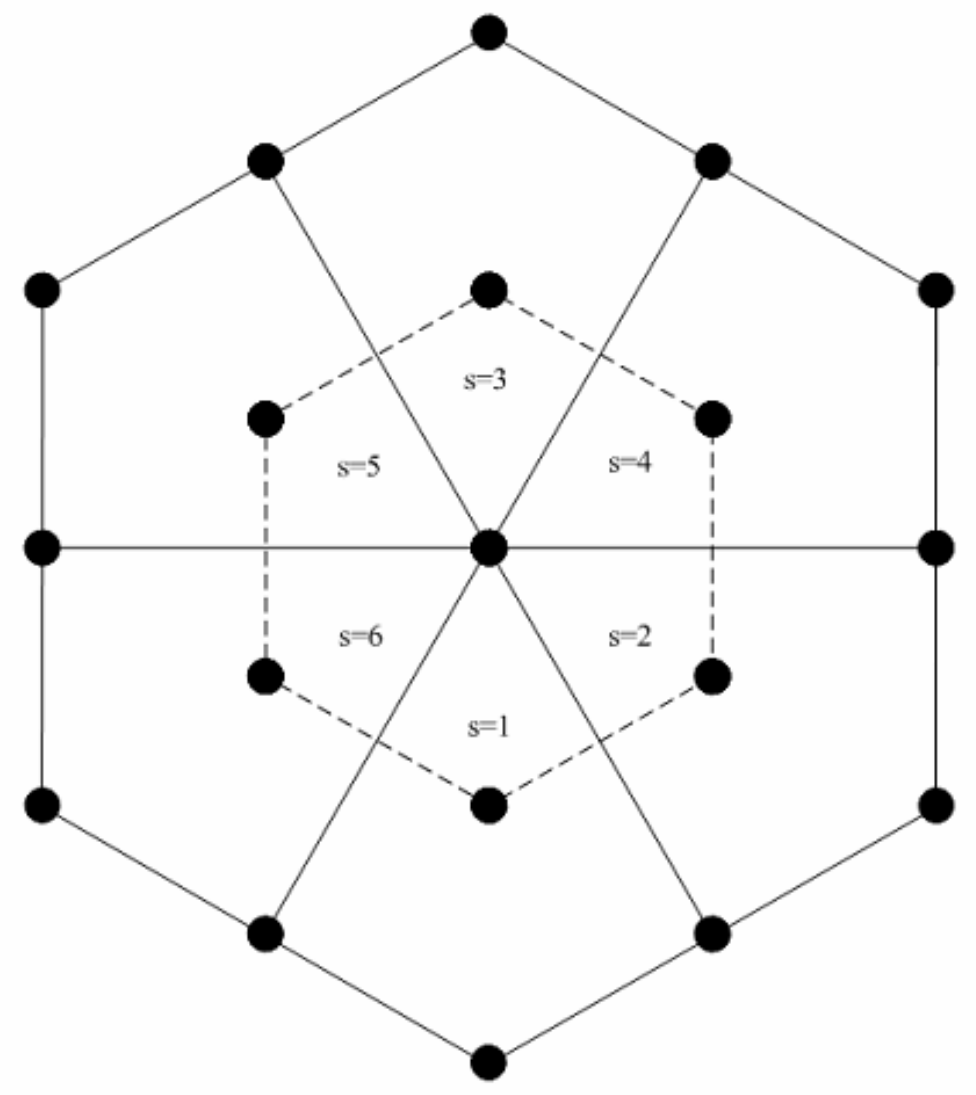

Figure 15 - Sectors for Space Vector Decomposition 
In [21], the projection of the commanded stator voltage onto the $a, b$ and $c$ axis determines in which sector the reference voltage lies. However, in this work, calculating $\theta$ using (3-2) can directly determine the sector based on (3-3). This approach is simpler to implement for simulation purposes, but more computationally expensive. The primary inverter will then use, as a reference voltage, the space vector pointing from the origin directly to that space vector state in that sector to reduce the required number of switching actions.

If given the constant DC link voltage, like in [21], (3-6) and (3-7) can compute the components of $v_{d q s 1}^{*}$. Then, manipulating (3-1) yields a reference voltage for the secondary inverter. However, with the addition of a boost converter module to the dual inverter drive, the controller must first calculate a reference value for the DC link voltages before performing these steps.

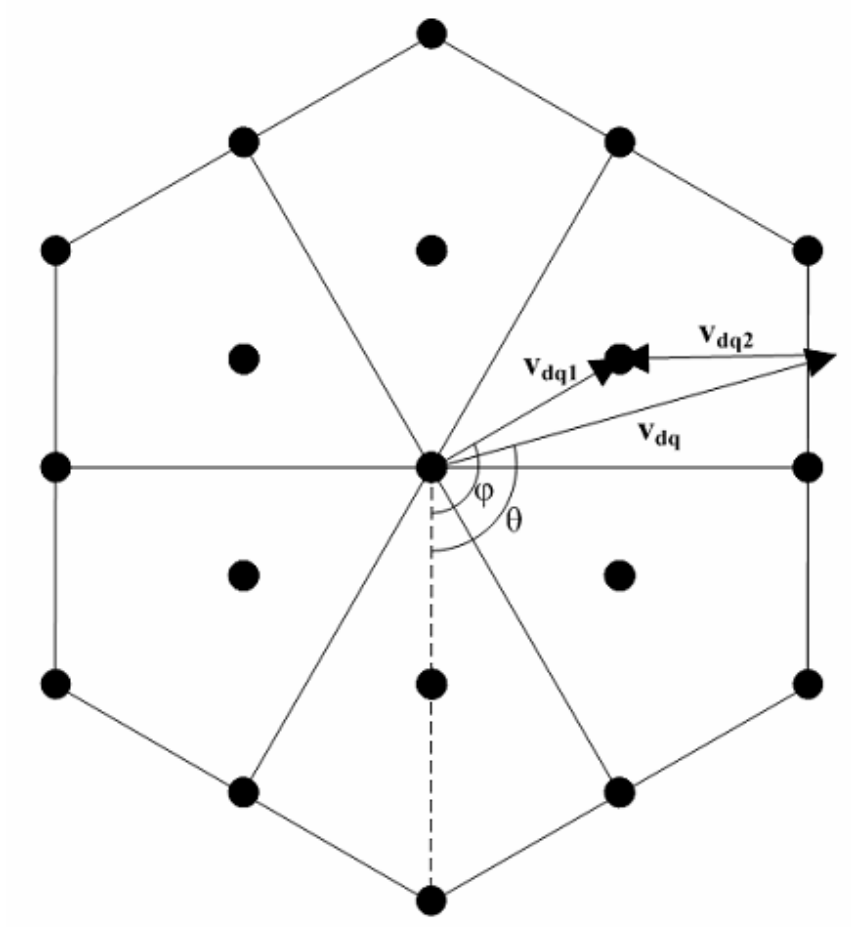

Figure 16 - Example Space Vector Decomposition for Proposed Controller 
Figure 16 shows a diagram of the resultant space vectors for an example $v_{d q s}^{*}$. The space vectors references form a triangle. Note that because $v_{d q s 1}^{*}$ points directly towards a space vector state, $\phi$ does not depend on the DC link voltages. Therefore, without any knowledge of the DC link voltages, the controller only knows the length of one side $\left(\left|v_{d q s}^{*}\right|\right)$ and one angle $(\phi-\theta$, or the angle between $v_{d q s}^{*}$ and $\left.v_{d q s 1}^{*}\right)$. This is an insufficient amount of information to determine the other sides and angles, so the controller must enforce a separate constraint to calculate the DC link voltages. To do so, the author chose to enforce equal DC link voltages at all times in order to draw approximately equal amounts of power from the batteries, although other sources show advantages of using unequal DC link voltages [3] or orthogonal references for $v_{d q s 1}^{*}$ and $v_{d q s 2}^{*}$ [1], [2]. Given the selected constraint, the voltage references now form an isosceles triangle, so (3-5) calculates the desired DC link voltage for a given stator voltage reference using trigonometric properties.

Practical limitations of the system constrain DC link voltage. Because of the operating range of the boost converter, the DC link voltage cannot be less than the battery voltage. Also, to limit the voltage stress on the switches, the controller restricts the DC link voltage to some maximum value, $V_{M A X}$. Now, (3-1) - (3-7) completely describe the stator voltage decomposition process.

$$
\begin{gathered}
\left|v_{d q s 1}^{*}\right|=\left|v_{d q s 2}^{*}\right| \\
\rightarrow V_{D C}^{*}=\min \left(\max \left(\left|v_{d q s}^{*}\right| * \frac{\sin (\phi-\theta)}{\sin (180-2(\phi-\theta))}, V_{B T}\right), V_{M A X}\right) \\
v_{d s 1}^{*}=\frac{V_{D C}^{*}}{2} \cos (\phi) \\
v_{q s 1}^{*}=\frac{V_{D C 1}^{*} \sin (\phi)}{2}
\end{gathered}
$$




\subsubsection{Task 4: Battery Current Calculator}

According to Section 2.3.1, hysteresis control of the boost converter inductor current can control the output voltage of a boost converter well. Therefore, the battery current, $I_{B T}$, can regulate the boost converter output voltage because the battery is in series with the boost inductor. Similar to the method used in [6] to calculate the maximum battery and DC link currents for a PMSM drive, lossless power balance equations approximate the required battery current, representing the hysteresis boundary. However, where [6] uses the torque and speed to calculate the power consumed by the motor, the control algorithm for this topology must use the stator voltage and current commanded for each inverter by Task 3 because the inverters may supply unequal amounts of power depending on the implementation of Task 3. Equations (3-8) quantifies these relationships in an average sense (denoted by the bar over variables), where the subscript $i$ can have a value of 1 or 2 referring to the primary or secondary drive, respectively. Definitions for the remaining reference values then follow from (3-8), shown in (3-9) and (3-10). The controller uses average values to reduce noise.

$$
\begin{aligned}
& P_{i}=V_{B T i} \cdot \overline{I_{B T \imath}}=\overline{V_{D C l}} \cdot \overline{I_{D C l}}=\frac{3}{2}\left(\overline{v_{d s l}^{r}} \cdot \overline{\iota_{d s l}^{r}}+\overline{v_{q s i}^{r}} \cdot \overline{\imath_{q s l}^{r}}\right) \\
& I_{D C i}^{*}=\frac{3}{2} \frac{\left(\overline{v_{d s l}^{*}} \cdot \overline{\boldsymbol{i}_{d s l}^{*}}+\overline{v_{q s i}^{*}} \cdot \overline{\boldsymbol{l}_{q s l}^{*}}\right)}{\overline{V_{D C l}^{*}}} \\
& I_{B T i}^{*}=\frac{3}{2} \frac{\left(\overline{v_{d s i}^{*}} \cdot \overline{\imath_{d s l}^{*}}+\overline{v_{q s i}^{*}} \cdot \overline{\imath_{q s l}^{*}}\right)}{V_{B T i}}
\end{aligned}
$$


In order to eliminate the steady state error in the DC link voltage, the author used a PI controller to adapt the battery current reference, $I_{B T i}^{*}$, based on the DC link current error [22]. The PI controller was manually tuned in simulation based on the transient response of the system. To protect the battery, the reference current in (3-10) should be limited to some maximum value $I_{B T, \max }$

\subsection{Comparison to Relevant PMSM Drives}

Limiting the DC link voltage, $V_{M A X}$, limits the speed range of the proposed drive. Various metrics, such as maximum device voltage stress, dictate the appropriate value for $V_{M A X}$ for a particular system. To compare the speed range to that of flux weakening control, the author proposes the use of the metric in (3-11) to estimate the maximum per unit speed of the dual inverter drive with a boost converter module based on $V_{M A X}$. Consider that the stator voltage, and therefore the DC link voltages, increases approximately proportional to the rotor speed according to (2-38), and that rotor and mechanical speed are related by (2-8). (3-11) therefore approximates the relationship between per unit voltage and per unit mechanical speed as a straight line. To account for the effects of rotor resistance at low speeds, the author sets the y-intercept equal to the stator voltage for a speed of $0 \mathrm{pu}$ and maximum torque (i.e. $i_{s n}=1$ ). With no rotation, the only non-zero term in (2-19) and (2-20) are the voltage drop across the resistance. Therefore, by Ohm's Law, the minimum normalized stator voltage, $V_{M I N}$, is equal to the normalized stator resistance, $R_{S n}$. 


$$
\begin{gathered}
V_{n} \cong m\left(\frac{2}{P} \omega_{m n}\right)+b \\
m=1 \frac{p u}{p u} \\
b=V_{M I N}=i_{s n, M A X} R_{s n}=R_{s n} p u \\
\rightarrow \omega_{M A X, V B}=\frac{P}{2}\left(\frac{V_{M A X}}{V_{b}}-R_{s n}\right) p u
\end{gathered}
$$

Below base speed, the drive achieves the MTPA condition without requiring a boost converter or flux weakening. Thus, all presented drives operate identically below base speed, except those drives with a DC/DC converter will incur extra losses in this region due to the presence of additional power electronics. Figure 17 shows an example phasor diagram in the rotor reference frame for this type of control based on the steady state of the circuits from Figure 5 and Figure 6 (i.e. ignoring the derivative term in (2-15)). Here, $j X_{S} I_{S}$ represents the combined voltage drop across both $L_{d}$ and $L_{q}$.

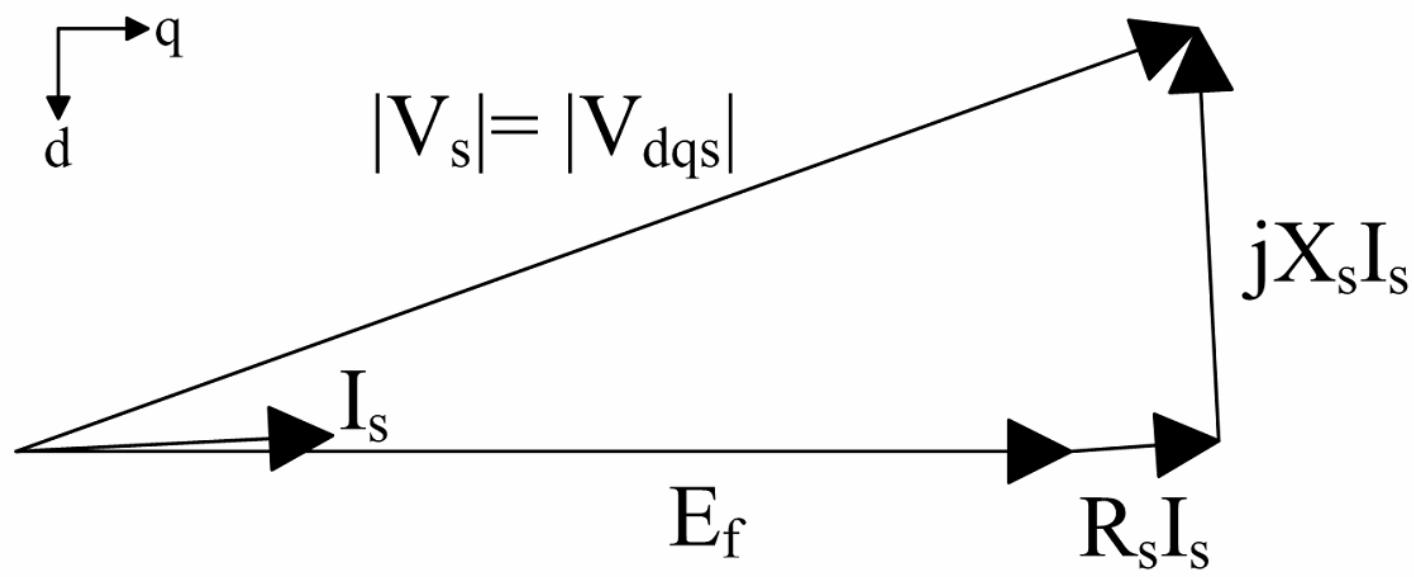

Figure 17 - Phasor Diagram Below Base Speed (MTPA)

Above base speed, the back EMF is too large for MTPA control without boosting the DC link voltage. Under flux weakening control, some stator current must generate flux that opposes 
the increasing back EMF of the motor instead of generating torque, shown in Figure 18. Thus, the drive supplies as much current above base speed as it does at base speed to provide constant power, but the torque production decreases because the controller diverts some of this current towards the direct axis (i.e. the angle of the stator current no longer satisfies the MTPA condition in (2-37)). Figure 19 approximates the capability curve of an OWPMSM motor when controlling it this way, if neglecting stator resistance. Recall that the maximum speed occurs when the angle of the stator current, $\delta$, is equal to $\pi$, meaning all current flows in the negative direction on the direct axis to maximally decreases the motor flux. The discontinuity in $\delta$ occurs as a result of ignoring resistance.

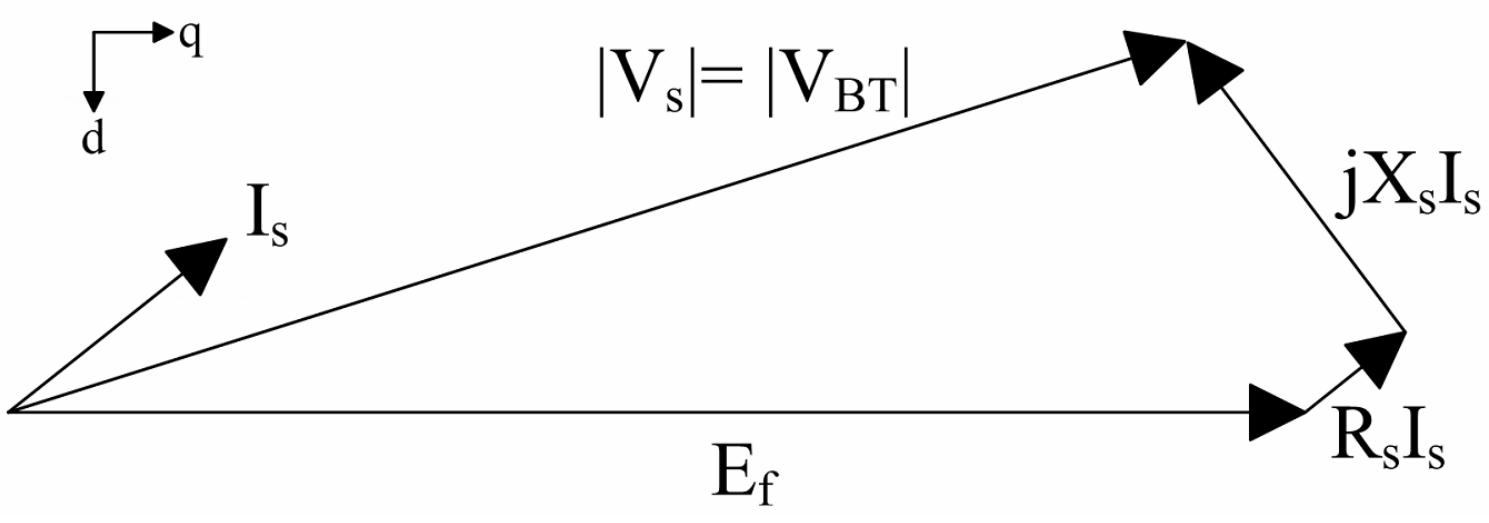

Figure 18 - Phasor Diagram Above Base Speed (Flux Weakening) 


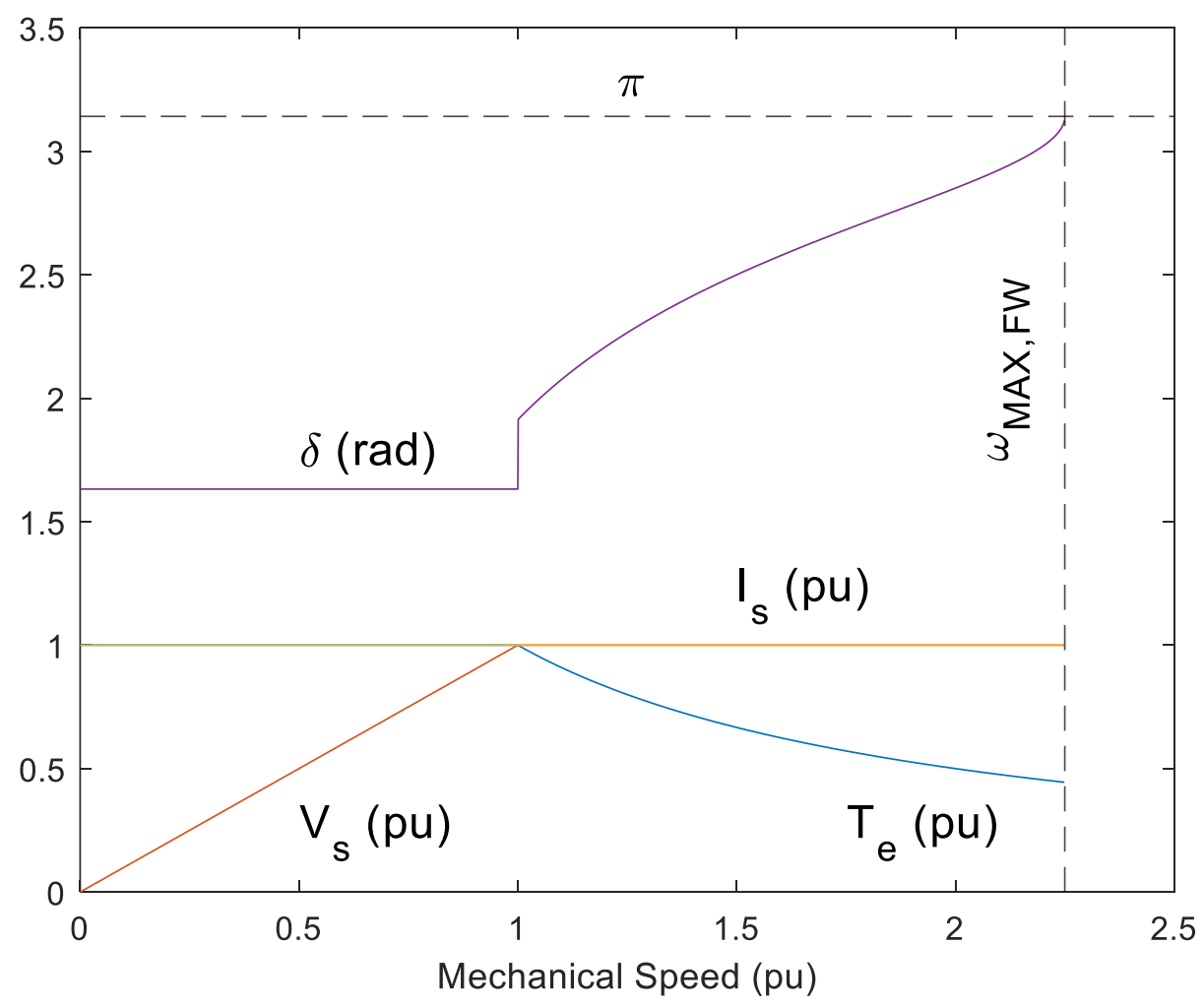

Figure 19 - Capability Curve for PMSM Drives with Flux Weakening

Instead, with a boost converter, the DC link voltage increases above base speed to allow the stator current to stay on the MTPA trajectory, shown in Figure 20. The proposed control can limit the battery current, $I_{B T}$, as needed to a maximum value, $I_{B T \text { max }}$, based on battery parameters. In these situations, according to the power balance equations (3-8) - (3-10), the maximum stator current decreases in order to boost the DC link voltage to provide constant maximum power above base speed. As a result, the value of the MTPA condition slightly changes as the stator current decreases according to (2-37). Furthermore, the maximum available torque is inversely proportional to speed due to the decrease in stator current. Thus, the torque production mimics that of flux weakening control, but the proposed drive uses less current to do so. This is expected to lower conduction losses in an OWPMSM as it has in a PMSM [6]. 
Figure 21 estimates this behavior graphically when neglecting stator resistance. The author selected the maximum DC link voltage $V_{M A X}$ to limit the speed to the same range as in Figure 19 for comparison. For an $\omega_{F W, M A X}=2.25 p u$ in Figure $19, V_{M A X} \cong 2.26$ based on (3-11). If the motor drive can supply a voltage higher than this $V_{M A X}$, it will improve the speed range of the drive compared to using flux weakening control. The following section will present a simulated example where the $V_{M A X}=6 p u$.

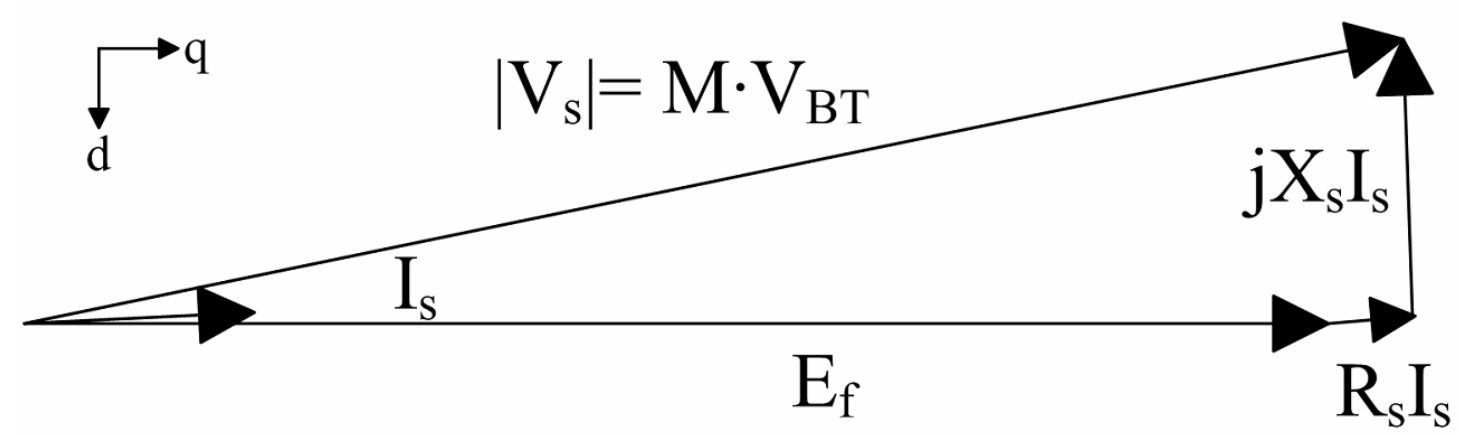

Figure 20 - Phasor Diagram Above Base Speed (Boost Converter Module) 


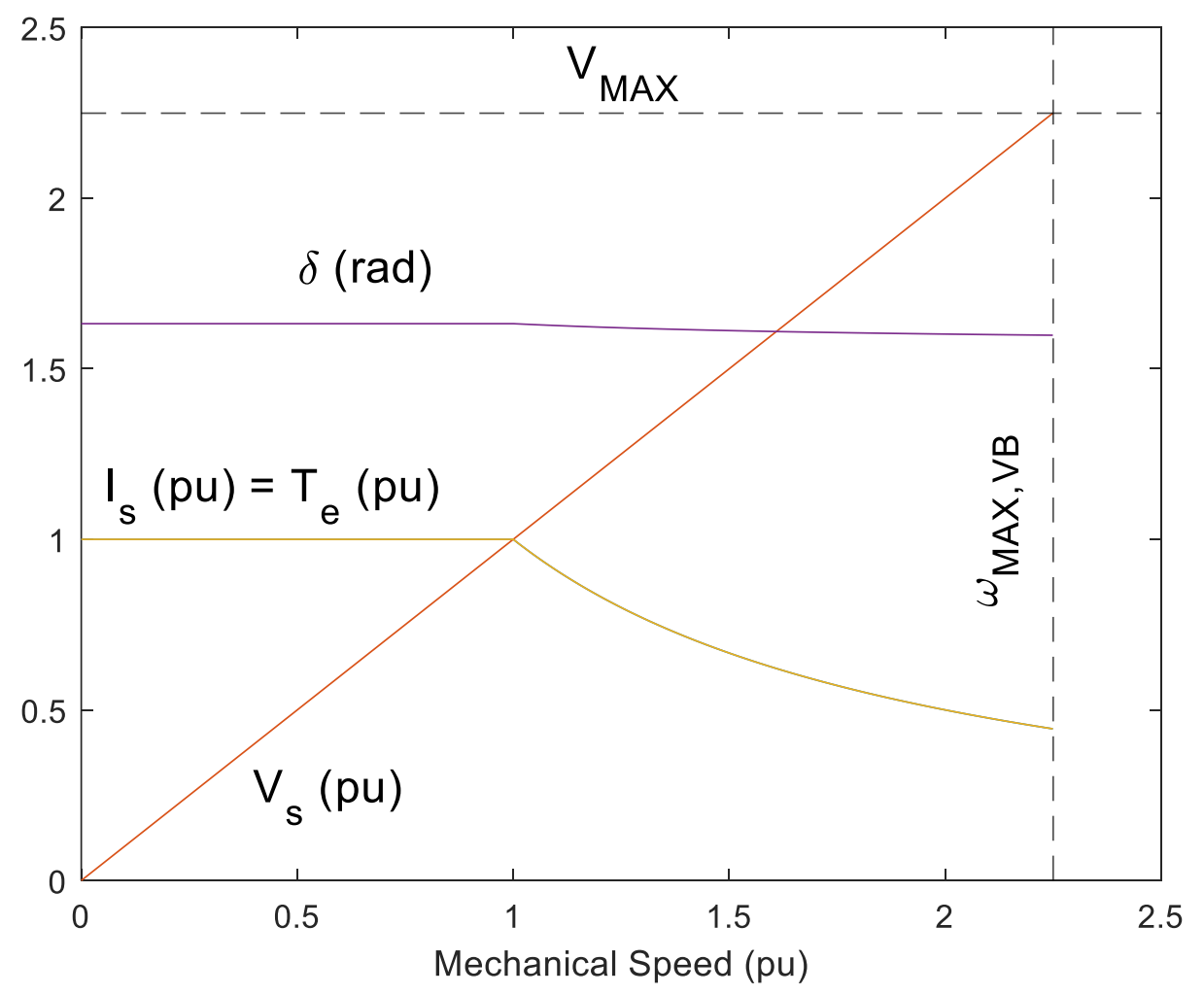

Figure 21 - Capability Curve for PMSM Drives with Boost Converter Modules 


\subsection{PLECS Simulation Results}

Table 1 - Necessary Simulation Parameters

\begin{tabular}{|c|c|c|}
\hline Parameter & Variable & Value \\
\hline Battery Voltage & $V_{B T 1}, V_{B T 2}$ & $200 \mathrm{~V}$ \\
\hline Maximum Battery Current & $I_{B T \text { max }}$ & $125 \mathrm{~A}$ \\
\hline Hysteresis Dead Band & $\Delta i_{L}$ & $2.5 \%$ \\
\hline Maximum DC Link Voltage & $V_{M A X}$ & $1200 \mathrm{~V}$ \\
\hline Poles & $P$ & $2 \mathrm{poles}$ \\
\hline Stator Resistance & $R_{S}$ & $14 \mathrm{~m} \Omega$ \\
\hline d-axis Stator Inductance & $L_{d}$ & $0.54 \mathrm{mH}$ \\
\hline q-axis Stator Inductance & $L_{q}$ & $0.60 \mathrm{mH}$ \\
\hline Rotor Flux Linkage & $\lambda_{a f}$ & $0.162 \mathrm{~Wb}-\mathrm{t}$ \\
\hline Friction Coefficient & $B$ & $0.01 \mathrm{Nm} / \mathrm{rad} / \mathrm{s}$ \\
\hline Rotor Moment of Inertia & $J$ & $0.0012 \mathrm{~kg} . \mathrm{m}^{2}$ \\
\hline Proportional Gain - Speed & $K_{p s}$ & 86.42 \\
\hline Integral Gain - Speed & $K_{i s}$ & $2.016 \mathrm{e} 5$ \\
\hline Proportional Gain - d-axis Current & $K_{p c d}$ & 63 \\
\hline Proportional Gain - q-axis Current & $K_{p c q}$ & 98 \\
\hline Integral Gain - Current & $K_{i c}$ & $1.633 \mathrm{e} 3$ \\
\hline Proportional Gain - Hysteresis & $K_{p h}$ & 0.1 \\
\hline Integral Gain - Hysteresis & $K_{i h}$ & 1 \\
\hline
\end{tabular}

Table 2 - Base Values for Machine Variables

\begin{tabular}{|c|c|c|}
\hline Parameter & Variable & Value \\
\hline Base Voltage & $V_{b}$ & $200 \mathrm{~V}$ \\
\hline Base Power & $P_{b}$ & $50 \mathrm{~kW}$ \\
\hline Base Current & $I_{b}$ & $166.67 \mathrm{~A}$ \\
\hline Base Speed & $\omega_{b}$ & $1,234.6 \mathrm{rad} / \mathrm{s}$ \\
\hline Base Torque & $T_{b}$ & $40.5 \mathrm{Nm}$ \\
\hline Base Impedance & $Z_{b}$ & $1.2 \Omega$ \\
\hline Base Inductance & $L_{b}$ & $0.972 \mathrm{mH}$ \\
\hline Base Flux Linkage & $\lambda_{b}$ & $0.162 \mathrm{~Wb}$ \\
\hline
\end{tabular}


A $50 \mathrm{~kW}$ OWPMSM, dual inverter drive with boost converter module and controller as described in this paper are simulated in PLECS using ideal switches. Compared to using the same battery to power both the primary and secondary inverter, using isolated DC sources significantly reduces the amount of common mode current (i.e. 0-axis current) in the motor [5], so the effects of the 0 -axis depicted in Figure 7 are ignored. Although high speed machines will often have 6 or more poles [2], the author chose to simulate a 2-pole machine to clearly demonstrate relationship between voltage and speed.

The parameters used are shown in Table 1 and were selected based on real machine parameters given in [2],[4] and [23]. Based on the parameters in Table 1, Table 2 gives the base values for necessary machine variables. The hysteresis dead band, $\Delta i_{L}$, was selected to limit the steady state switching frequency. Table 1 also includes all PI gains. Section 2.2.1 gives equations for current and speed PI gains based on the parameters in Table 1. However, the author manually tuned the PI controller for the hysteresis band, first determining $K_{p h}$ according to the settling time and then determining $K_{i h}$ according to the steady state error.

With the boost converter module, the dual inverter drive achieves the stated objective of extending the speed range while maintaining the MTPA condition for all speeds. Figure 22 compares predicted and simulated values for torque-speed. Figure 23 shows the transient response of the motor to a step change in the speed, demonstrating the drive follows the torque-speed curve even during abrupt changes in operating points, as is common in EVs [4]. For the parameters given in Table 1, the maximum speed without the boost converter modules was about 2.25 pu according to (2-45). Thus, given devices that can withstand the voltage stress imposed by the presented control strategy for the given value of $V_{M A X}$, the boost converter modules can significantly extend the speed range. 


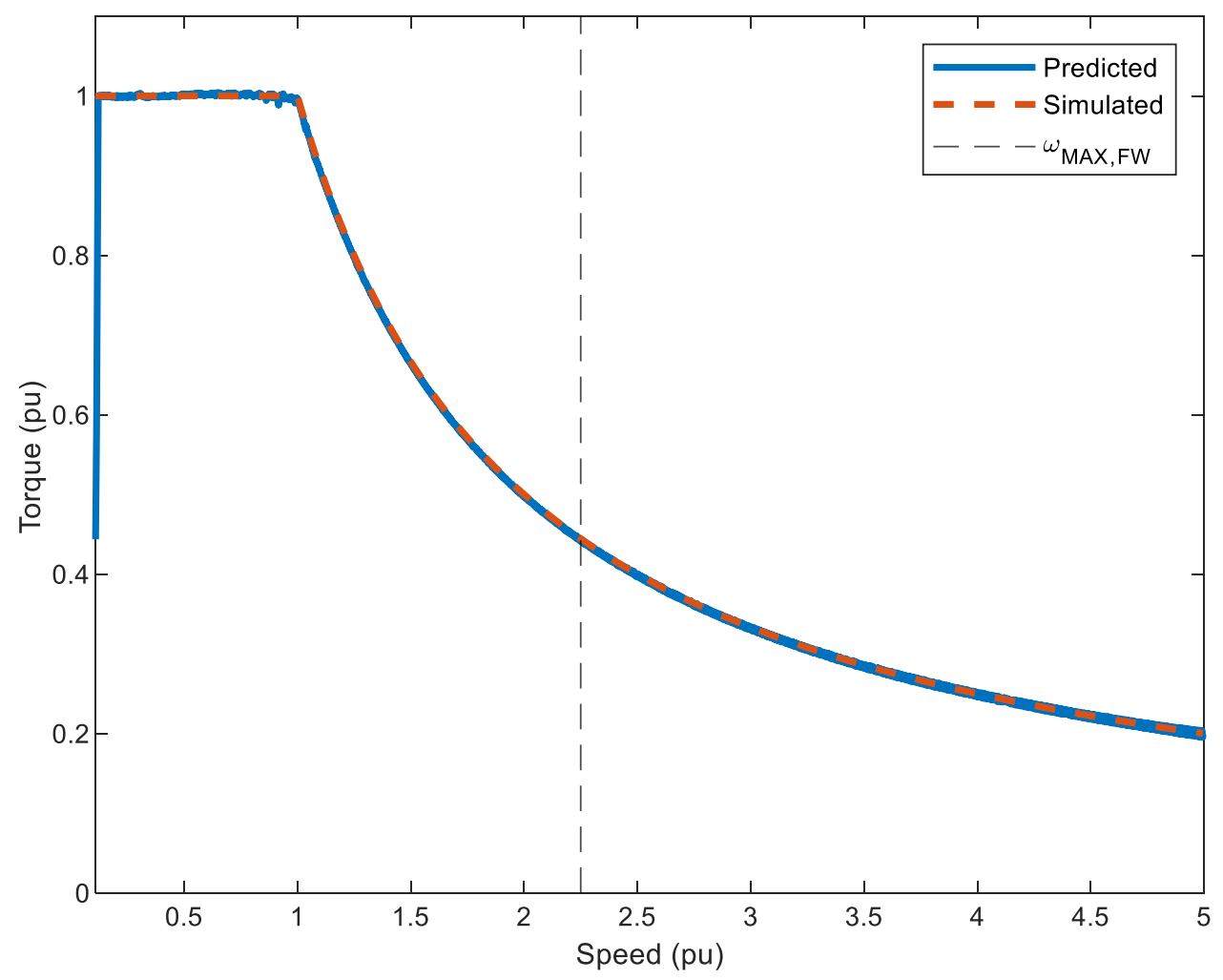

Figure 22 - Torque-Speed Curve for Dual Inverter Drive with Boost Converter Modules 

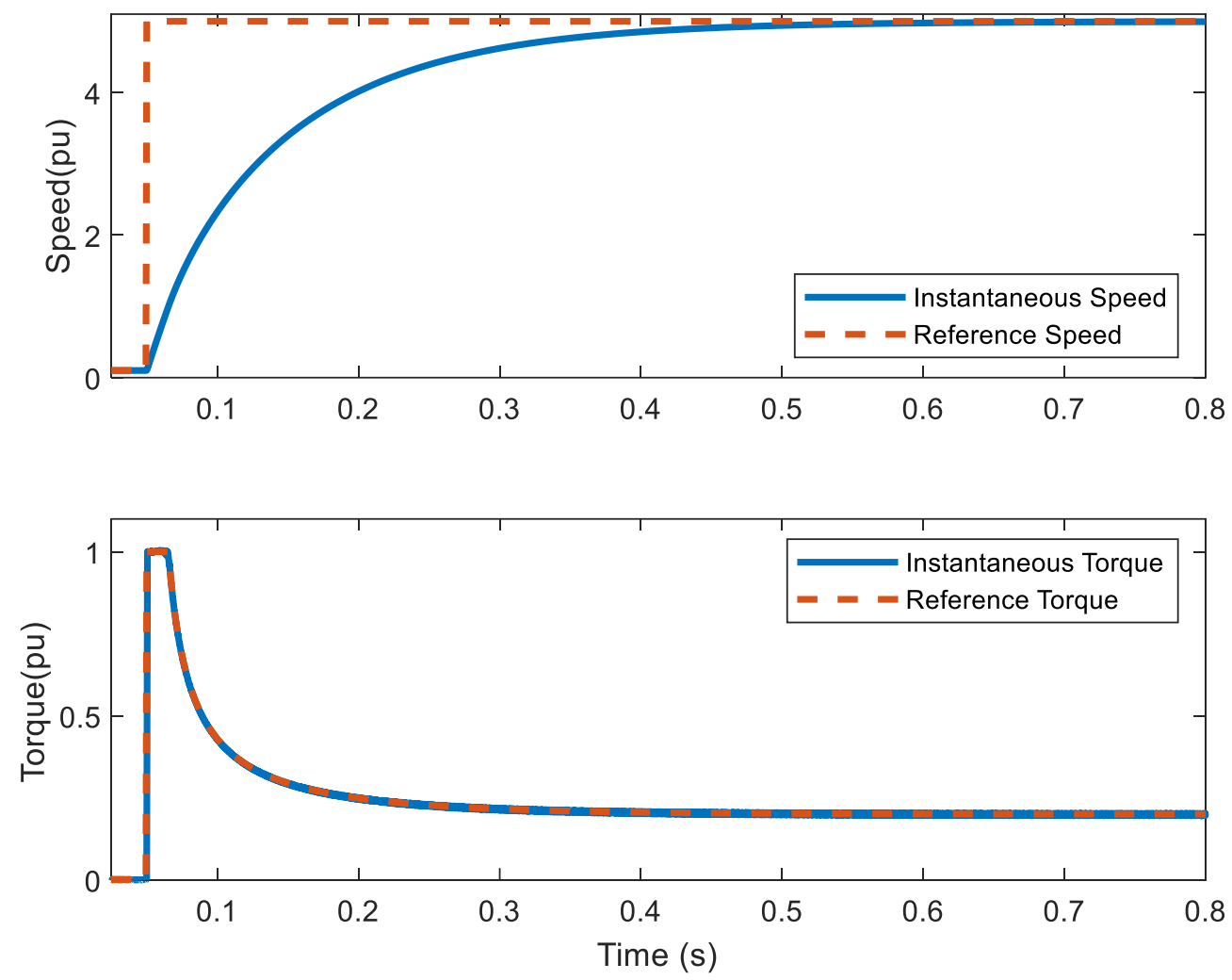

Figure 23 - Step Response for Speed and Resultant Torque Production

Similarly, Figure 24 shows the power production vs speed for the proposed topology. As suggested by Figure 21, the power increases linearly with speed below base speed because torque is constant, but above base speed, power production is constant because torque production is inversely proportional to speed according to Figure 21. Power production deviates slightly from the predicted behavior initially after the step change, increasing linearly but with some constant error. However, this error gradually eliminated as the DC link voltage begins to increase and the drive starts producing a constant power output. 


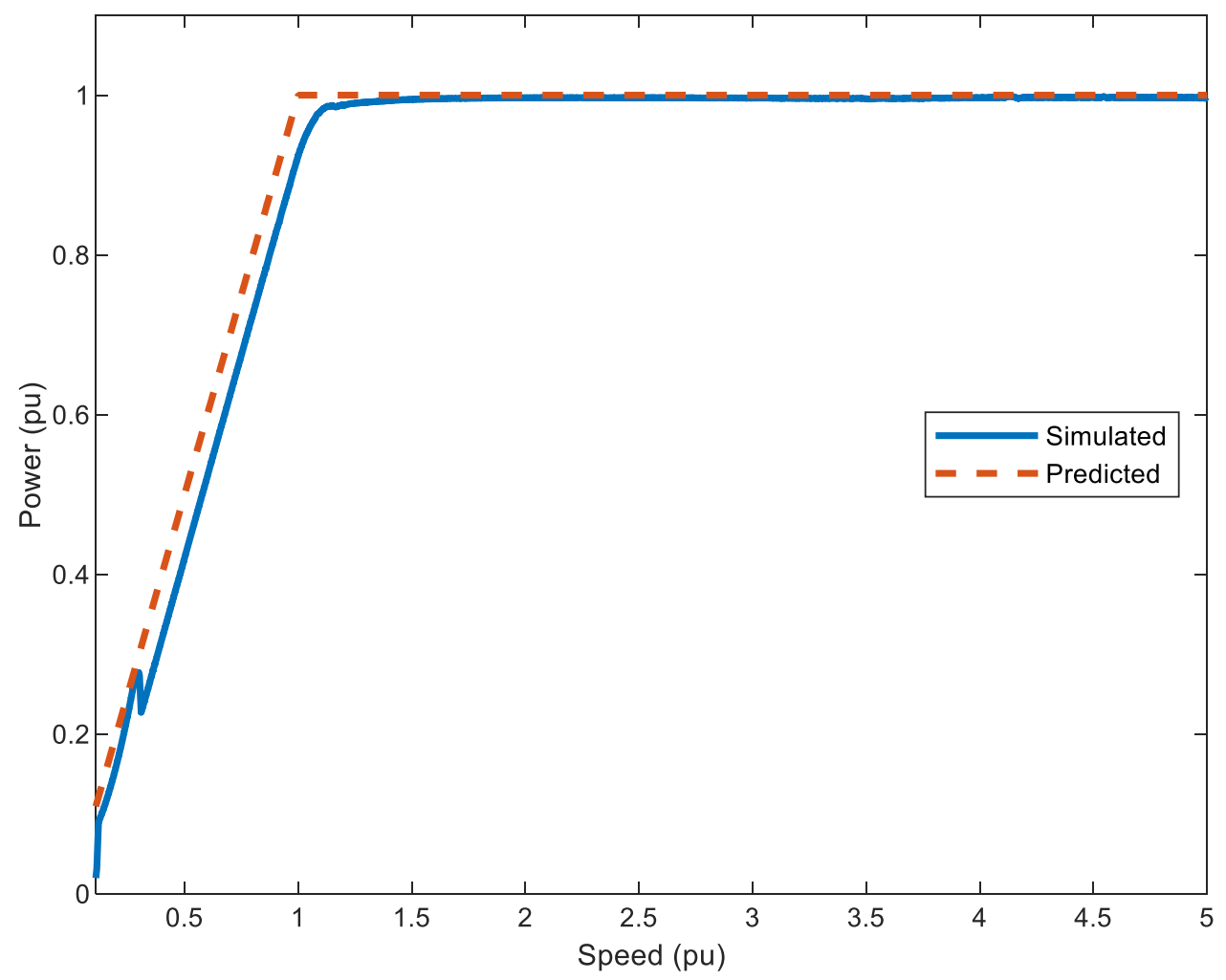

Figure 24 - Power Production vs. Speed for Dual Inverter Drive with Boost Converter Modules

Figure 25 and Figure 26 demonstrate that the other state variables, the d- and q-axis currents, behave as expected. Figure 25 shows the simulated stator current magnitude and compares the angle of the current, $\delta$, to the MTPA condition in (2-37) for all speeds. Below base speed, the drive behaves as expected. However, when the difference between $L_{d}$ and $L_{q}$ is more significant (e.g. $L_{d}=2 L_{q}$ ), the stator current is slightly lower than expected below base speed, despite torque production agreeing with predictions. Above base speed; fluctuations in the current angle become increasingly significant as speed increases, but the average value of the measured stator current angle follows the MTPA condition. Then, to verify the sinusoidal current production, Figure 26 shows example steady state phase currents for the OWPMSM. 

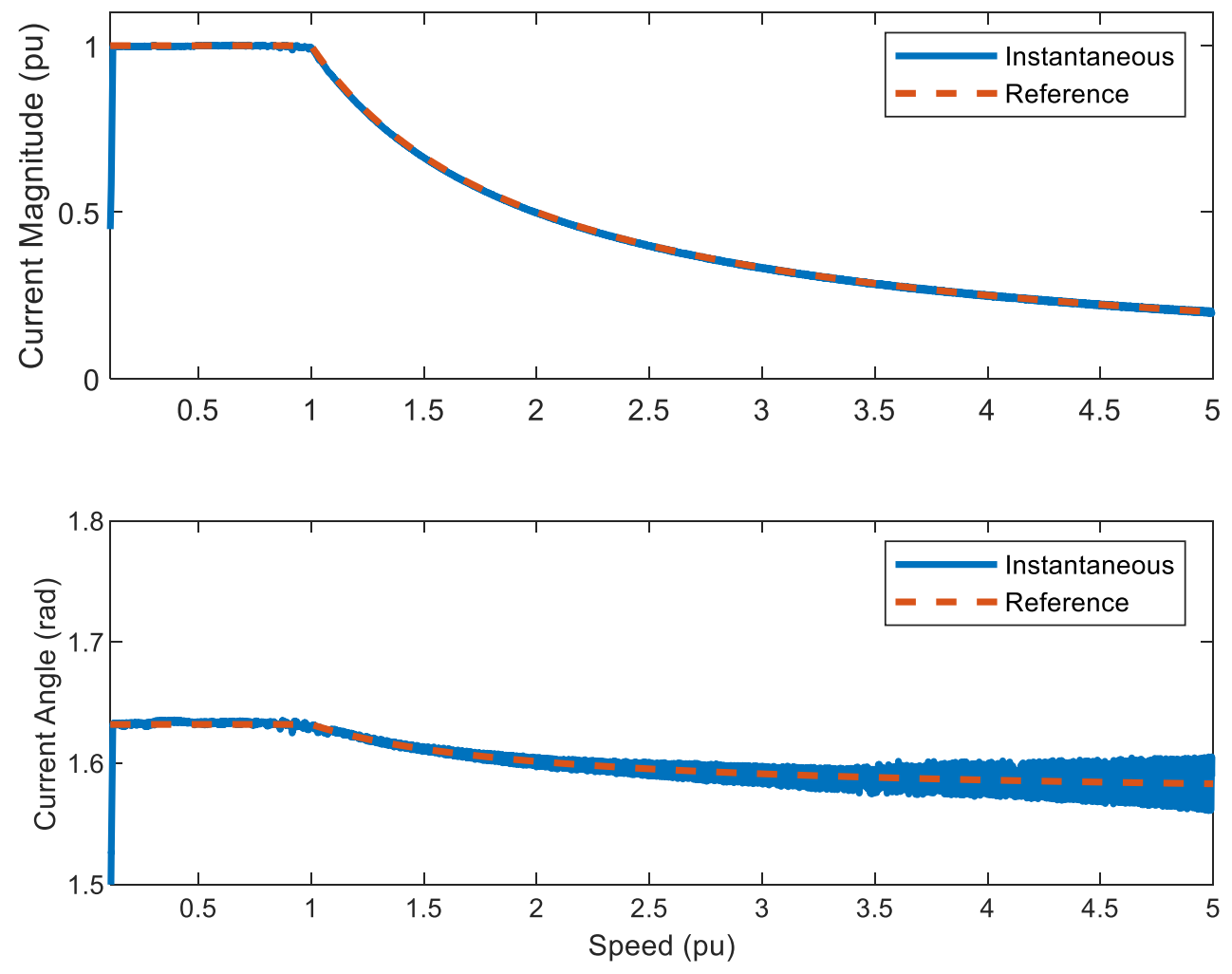

Figure 25 - Stator Magnitude and Angle vs. Speed 


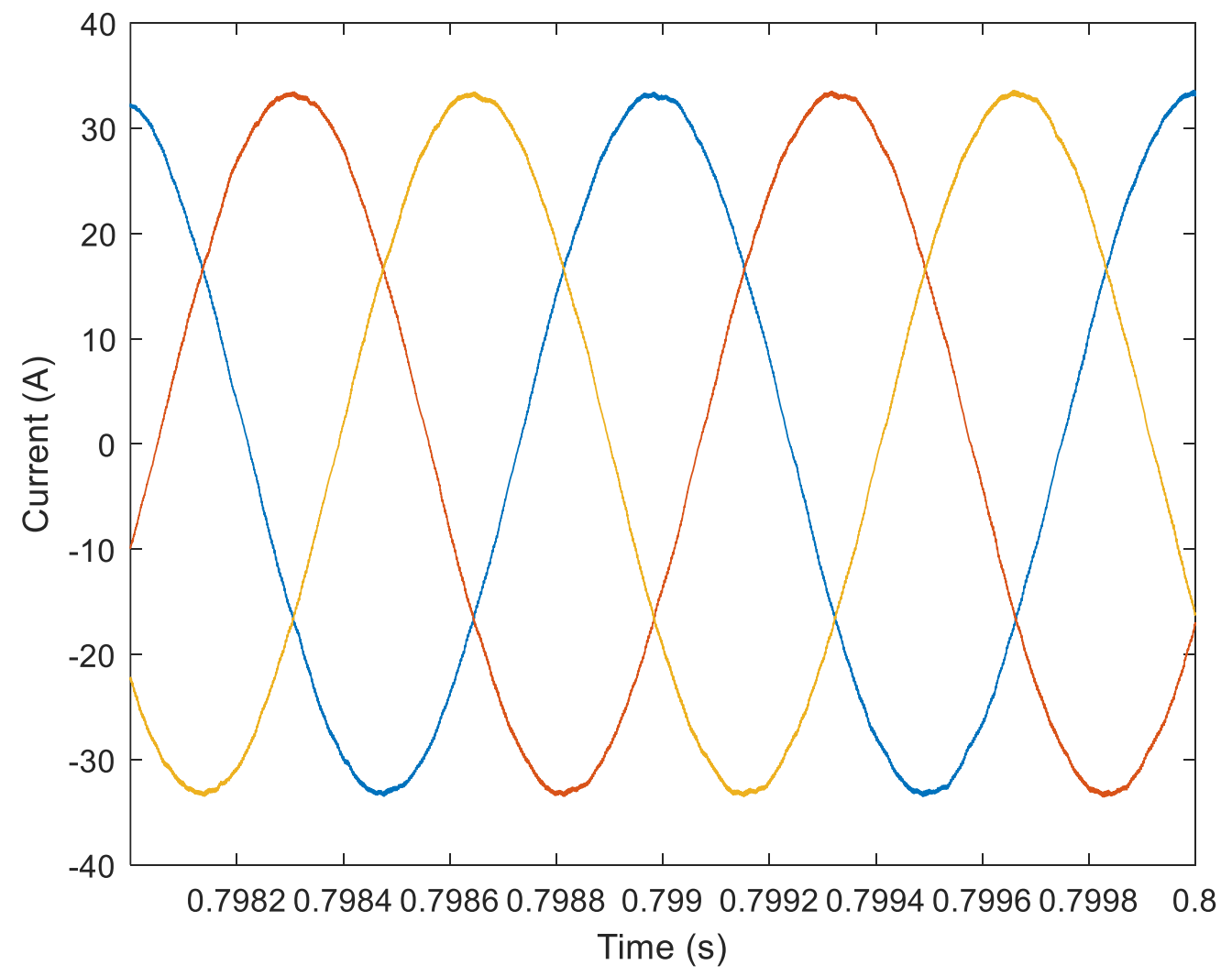

Figure 26 - Steady State Phase Currents vs. Time

To illustrate the operation of the boost converter module, Figure 27 shows the stator voltage and to the DC link voltages during the same step change in speed from Figure 23. The step change in speed reference initially causes significant fluctuations in the DC link voltage reference (most notably between speeds of $1 \mathrm{pu}$ and $2 \mathrm{pu}$ in Figure 28). However, by about $0.15 \mathrm{~s}$ after the step change, the PI controller has adapted the current references accordingly, and the DC link voltages then increase proportional to the speed, as expected. Regardless of these unexpected effects, the actual voltage applied to the stator increases relatively smoothly as speed increases. At steady state, the stator voltage deviates from the predicted value by about $3.1 \%$ while the DC link voltages deviate from predictions by about $1.8 \%$. 
Figure 28 shows this same voltage data from Figure 27 as a function of instantaneous speed instead of time. In this plot, the predicted voltage is calculated using the same linear approximation used to predict the maximum speed in (3-11). While transient events discussed previously causes a disparity between predictions and the actual stator voltage at low speeds, the two converge to a reasonable at higher speeds after transient behavior has settled (again, about 3.1\% error). Therefore, the author accept (3-11) as a reasonable estimate of the maximum speed range when boosting the DC link voltage, although the actual maximum speed may be slightly lower than the value given by the proposed metric. 

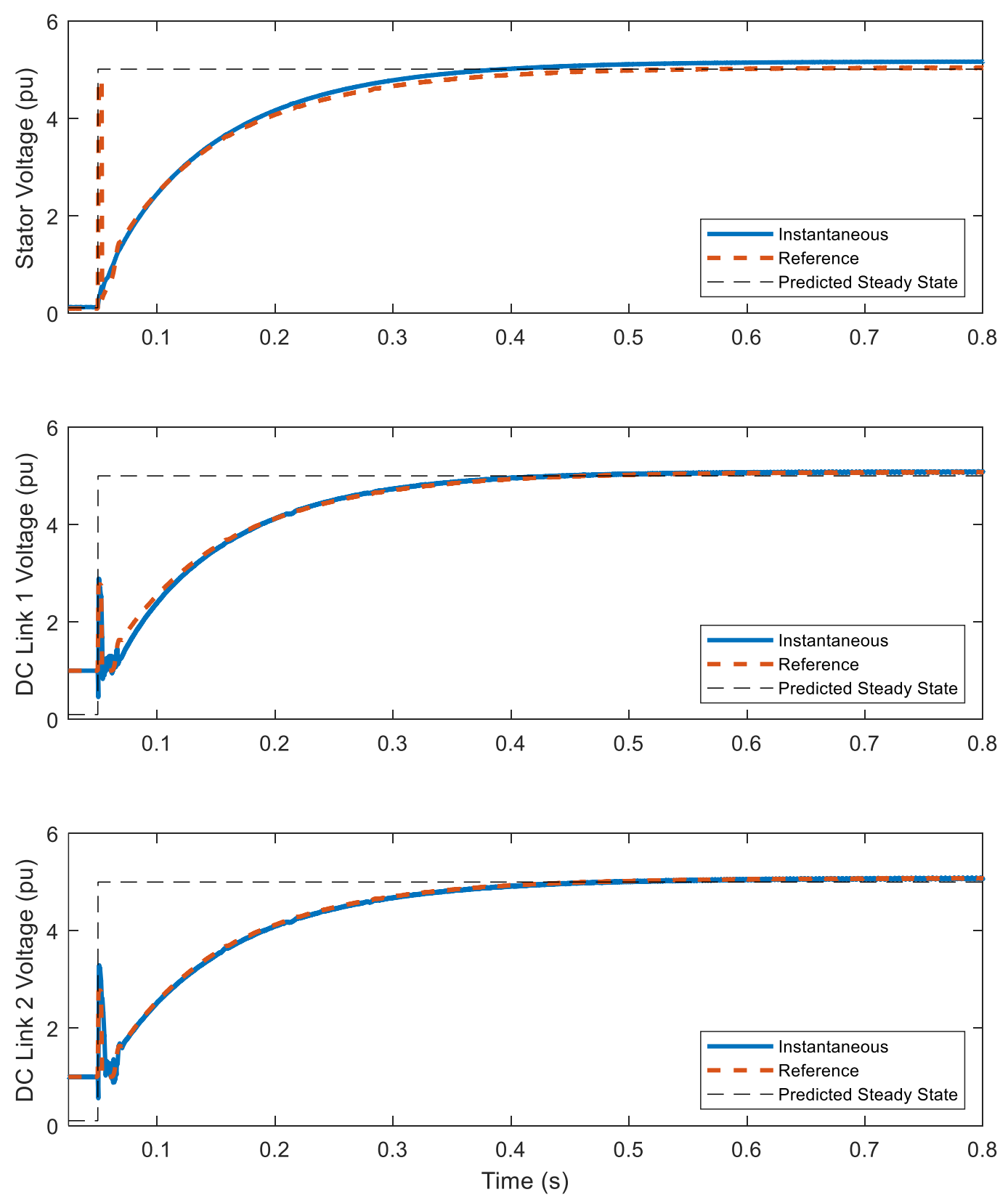

Figure 27 - Resultant Voltages During Step Change in Speed 

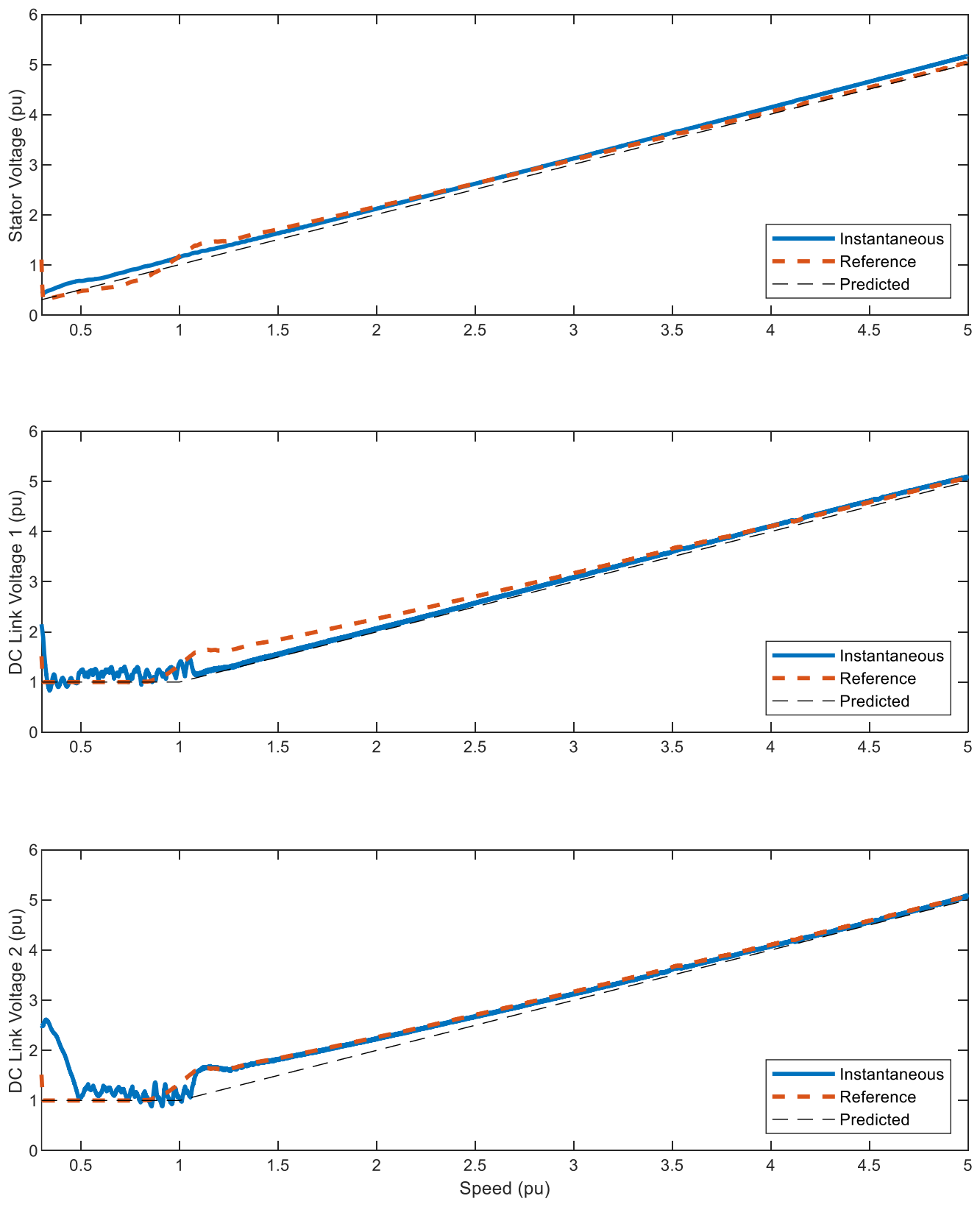

Figure 28 - Voltage vs. Speed During a Step Change in Voltage 
Figure 29 further verifies the operation of the boost converter module by showing the battery current during the same step change. This current is limited to the value $I_{B T \max }$ in Table 1 in order to mimic both the constant power production of flux weakening control and the current limits of Li-based batteries. The results clearly show that, aside from an initial spike in current immediately after the step change, the controller limits the battery current well.
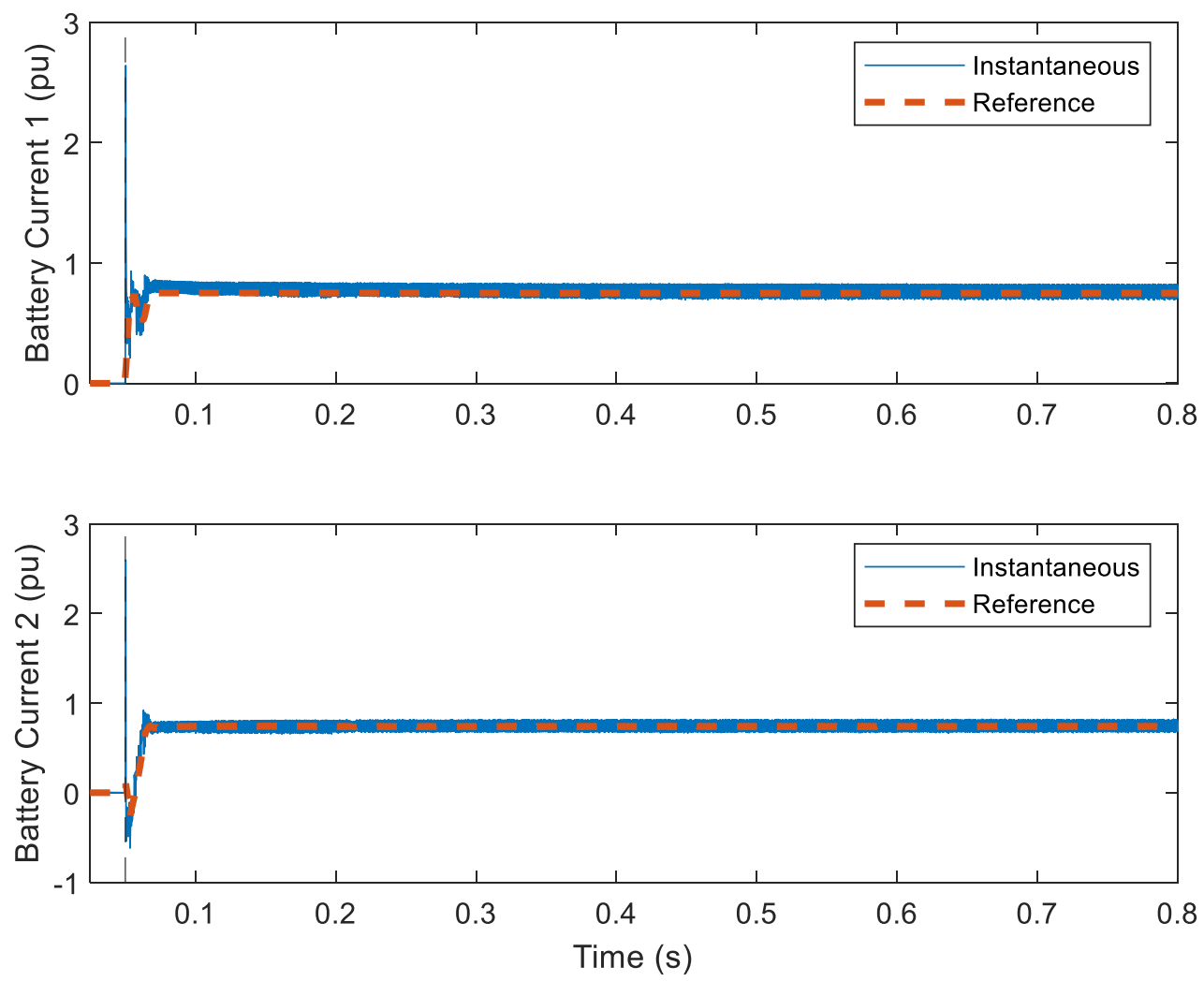

Figure 29 - Battery Current During a Step Change in Speed

Finally, Figure 30 shows an example switching function for the boost converter modules. The switching frequency is not constant, as expected when using hysteresis control. By observation, the maximum switching frequency is about $400 \mathrm{kHz}$ for the parameters in Table 1. 
This may be too high for practical applications, and may require the use of methods that limit the switching frequency of hysteresis controllers. The simplest approach is to increases the size of the hysteresis dead band as needed. Preliminary testing shows increasing the dead band from $\Delta i_{L}=$ $2.5 \%$ to $\Delta i_{L}=5 \%$ decreases the maximum switching frequency to about $100 \mathrm{kHz}$, a more practical target. While this approach is easy to implement, the type of power source used may impose restrictions on the amount of current ripple and, hence, the switching frequency.

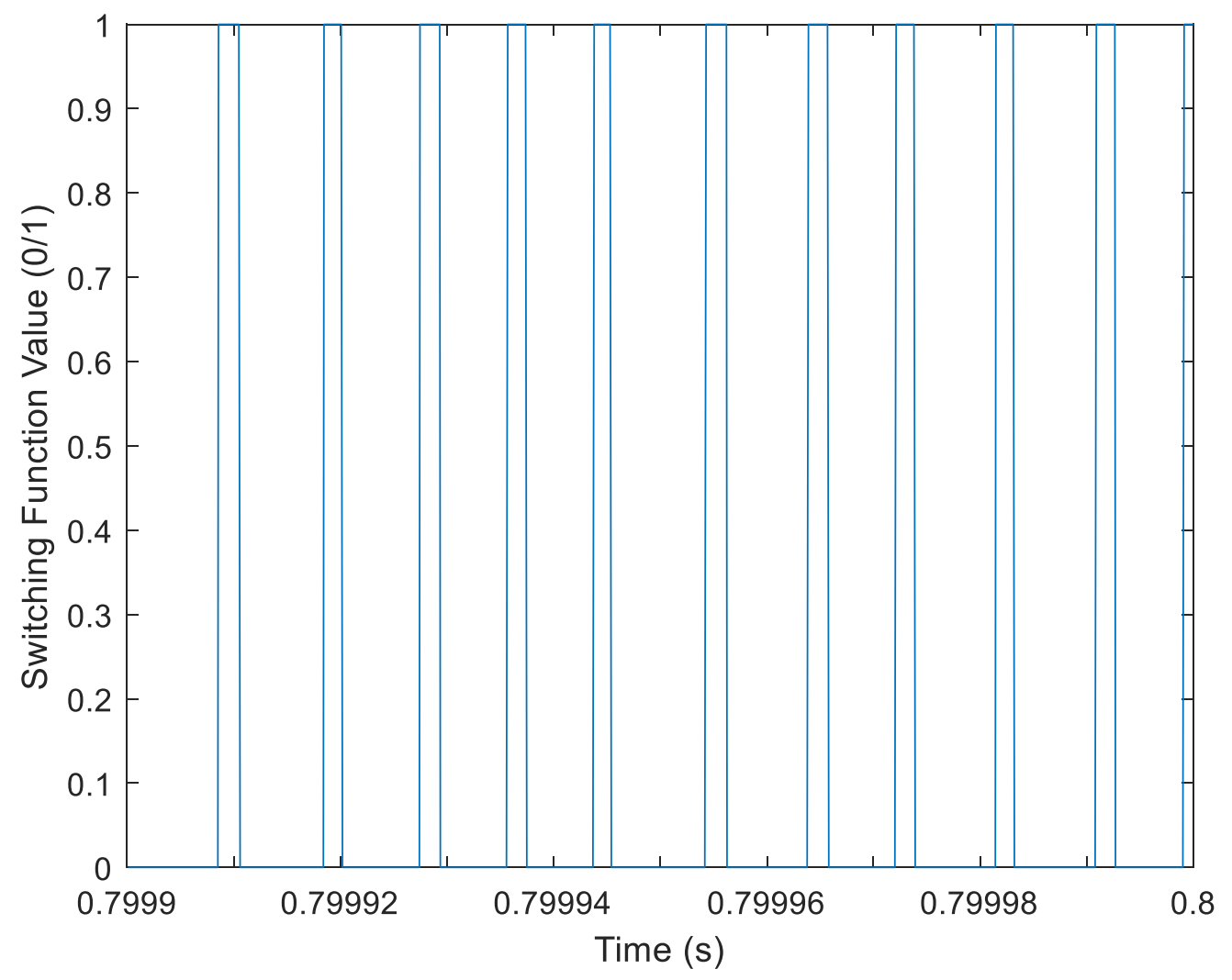

Figure 30 - Switching Funciton at Steady State for Boost Converter Module 


\subsection{Conclusion}

This work expands the theory of operation of a boost converter in a PMSM motor drive to function in a dual inverter drive for an OWPMSM. In this work, the author proposed a new topology and control scheme for the dual inverter drive to ensures voltage regulation of both DC link voltages while limiting the battery current for protection. By boosting the DC link voltage, the drive can always maintain the MTPA condition at all speeds. Because the battery current is limited, the maximum available stator current decreases while boosting the DC link voltage in order to maintain power balance. However, by maintaining the MTPA condition, the torque production matches that of flux weakening control, but the proposed drive uses less current to do so. Hence, conduction losses in the motor decrease compared to the dual inverter drive without a boost converter module.

A metric is proposed to estimate the speed range based on the maximum allowable DC link voltage. This maximum DC link voltage can depend on a variety of factors, such as maximum allowable semiconductor voltage stress. If this maximum DC link voltage is high enough, the proposed drive extends the speed range of the dual inverter drive compared to flux weakening control in addition to lower conduction losses. Simulation in PLECS shows, for practical machine parameters, the proposed drive significantly extends the speed range. 


\section{Bibliography}

[1] B. A. Welchko, "A double-ended inverter system for the combined propulsion and energy management functions in hybrid vehicles with energy storage," in 31 st Annual Conference of IEEE Industrial Electronics Society, 2005.

[2] S. P. Joon and N. Kwangnee, "Dual inverter strategy for high speed operation of HEV permanent magnet synchronous motor," Conference Record - IAS Annual Meeting (IEEE Industry Applications Society), vol. 1. pp. 489-494, 2006.

[3] K. A. Corzine, S. D. Sudhoff, and C. A. Whitcomb, "Performance characteristics of a cascaded two-level converter," IEEE Transactions on Energy Conversion, vol. 14, no. 3. pp. 433-439, 1999.

[4] H. Chen, H. Kim, R. Erickson, and D. Maksimovic, "Electrified Automotive Powertrain Architecture Using Composite DC-DC Converters," IEEE Trans. Power Electron., vol. 32, no. 1, pp. 98-116, Jan. 2017.

[5] B. Wang et al., "Overall assessments of dual inverter open winding drives," in 2015 IEEE International Electric Machines \& Drives Conference (IEMDC), 2015, pp. 1029-1035.

[6] K. Yamamoto, K. Shinohara, and H. Makishima, "Comparison between flux weakening and PWM inverter with voltage booster for permanent magnet synchronous motor drive," in Proceedings of the Power Conversion Conference-Osaka 2002 (Cat. No.02TH8579), 2002, pp. 161-166.

[7] R. Krishnan, Permanent Magnent Synchronous and Brushless DC Motor Drives, 1st ed. Boca Raton, FL: CRC Press, 2009.

[8] J. Cao, N. Schofield, and A. Emadi, "Battery balancing methods: A comprehensive review," in 2008 IEEE Vehicle Power and Propulsion Conference, 2008, pp. 1-6.

[9] J. Hong, H. Lee, and K. Nam, "Charging Method for the Secondary Battery in Dual-Inverter Drive Systems for Electric Vehicles," IEEE Trans. Power Electron., vol. 30, no. 2, pp. 909$921,2015$.

[10] R. Reisinger and A. Emadi, "Sensible Transportation Electrification: Get rid of inefficient powertrain designs," IEEE Electrification Magazine, vol. 1, no. 2. pp. 6-12, 2013.

[11] S. M. Lukic, J. Cao, R. C. Bansal, F. Rodriguez, and A. Emadi, "Energy Storage Systems for Automotive Applications," IEEE Trans. Ind. Electron., vol. 55, no. 6, pp. 2258-2267, 2008. 
[12] S. Wang and P. W. Lehn, "Design and Control of 3-Phase Integrated Charger for DualInverter Drivetrain Electric Vehicles.” pp. 1-6, 2019.

[13] C. Viana, M. Keshani, and P. W. Lehn, "Interleaved buck-boost integrated dc fast charger with bidirectional fault blocking capability," 2019 IEEE 20th Workshop on Control and Modeling for Power Electronics, COMPEL 2019. 2019.

[14] F. Caricchi, F. Crescimbini, G. Noia, and D. Pirolo, "Experimental study of a bidirectional $\mathrm{dc}$-dc converter for the dc link voltage control and the regenerative braking in PM motor drives devoted to electrical vehicles," Conference Proceedings - IEEE Applied Power Electronics Conference and Exposition - APEC, vol. 1. pp. 381-386, 1994.

[15] J. Zhu, H. Kim, H. Chen, R. Erickson, and D. Maksimovic, "High efficiency SiC traction inverter for electric vehicle applications," Conference Proceedings - IEEE Applied Power Electronics Conference and Exposition - APEC, vol. 2018-March. pp. 1428-1433, 2018.

[16] A. Yazdani and R. Iravani, Voltage-Sourced Converters in Power Systems: Modeling, Control and Applications, 1st ed. Hoboken, NJ: Wiley-IEEE Press, 2010.

[17] S.-H. Kim, Electric Motor Control. Cambridge, MA: Elsevier Science, 2017.

[18] R. W. Erickson and D. Maksimovic, Fundamentals of Power Electronics, 2nd ed. New York: Kluwer Acadmeic/Plenum Publishers, 2004.

[19] P. T. Krein, Elements of Power Electronics. New York city: Oxford University Press, 1998.

[20] M. Forouzesh, Y. P. Siwakoti, S. A. Gorji, F. Blaabjerg, and B. Lehman, "Step-Up DC-DC Converters: A Comprehensive Review of Voltage-Boosting Techniques, Topologies, and Applications," IEEE Trans. Power Electron., vol. 32, no. 12, pp. 9143-9178, 2017.

[21] A. S. Aneesh Mohamed, A. Gopinath, and M. R. Baiju, "A simple space vector PWM generation scheme for any general n-level inverter," IEEE Transactions on Industrial Electronics, vol. 56, no. 5. pp. 1649-1656, 2009.

[22] A. A. Boora, F. Zare, and A. Ghosh, "Application of dynamic hysteresis band height control to improve output voltage transient in boost and Positive Buck-Boost converters," in 2009 13th European Conference on Power Electronics and Applications, 2009, pp. 1-8.

[23] J. Agrawal and S. Bodkhe, "Functional modeling and simulation of inverter fed permanent magnet synchronous motor drive," in 2014 Annual International Conference on Emerging Research Areas: Magnetics, Machines and Drives (AICERA/iCMMD), 2014, pp. 1-6. 